\title{
European Review of Social Psychology
}

\section{Confirmation as coping with competition}

\section{Fabrizio Butera, Nicolas Sommet \& Claudia Toma}

To cite this article: Fabrizio Butera, Nicolas Sommet \& Claudia Toma (2018) Confirmation as coping with competition, European Review of Social Psychology, 29:1, 299-339, DOI: 10.1080/10463283.2018.1539908

To link to this article: https://doi.org/10.1080/10463283.2018.1539908

曲 Published online: 14 Nov 2018.

Submit your article to this journal

山 Article views: 23

View Crossmark data 


\title{
ARTICLE
}

\section{Confirmation as coping with competition}

\author{
Fabrizio Butera ${ }^{a}$, Nicolas Sommet ${ }^{a, b}$ and Claudia Toma ${ }^{c}$ \\ aLaboratoire de Psychologie Sociale (UNILaPS), Université de Lausanne, 1015 Lausanne, \\ Switzerland; 'Life Course and Inequality Research Centre (LINES), Université de Lausanne, \\ 1050 Lausanne, Switzerland; 'Solvay Brussels School of Economics and Management, \\ Université libre de Bruxelles, 1015 Bruxelles, Belgium
}

\begin{abstract}
Confirmation is a widespread tendency to seek, use, interpret or remember information in such a way as to corroborate one's hypothesis. We review various conceptions of confirmation and classify them as a function of whether they depict this phenomenon as a cognitive failure, a form of motivational prioritisation, or a pragmatic strategy. Then, we note that such a systematic and pervasive phenomenon must be a central mechanism of human activity serving an important and specific social function. We propose that confirmation is an adaptive mechanism that serves the function of coping with competitive situations. This general proposition is broken down into three implications: Confirmation occurs to a larger extent (1) when there is competition, (2) when competition is threatening, (3) when competition threatens one's feelings of competence. A research programme is reported to illustrate each of these implications.
\end{abstract}

ARTICLE HISTORY Received 20 February 2018; Accepted 21 October 2018

KEYWORDS Confirmation; competence; threat; competition; coping

Testing ideas, beliefs and hypotheses by gathering evidence in physical or social reality is a major feature of everyday life. Citizens look for information that is likely to enlighten their political choices, physicians check their diagnoses against observable symptoms, and scientists test their hypotheses by collecting relevant data. Notwithstanding the diversity of actors, goals, and tests depicted in the above examples, a common phenomenon consistently appears from a sizable body of literature in cognitive and social psychology: People display a tendency to confirm their hypotheses. This phenomenon can be defined as the tendency to "search for, interpret or remember information in such a way that the corroboration of a hypothesis becomes likely, independent of its truth" (Oswald \& Grosjean, 2004, p. 93). Interestingly, such a definition points out that, in the process of testing their

CONTACT Fabrizio Butera fabrizio.butera@unil.ch E Université de Lausanne, IP-SSP, Geopolis, CH 1015 Lausanne, Switzerland

(c) 2018 European Association of Social Psychology 
hypotheses in a confirmatory manner, citizens may end up voting for a candidate that is not as honest as they believed, physicians may recommend a treatment that is inappropriate for their patient, and scientists may reach conclusions that are not sustained by solid evidence. It then appears that the consistency and potential for harm of such a phenomenon are conspicuous, and indeed several lines of research have attempted to account for its occurrence.

In this article, we present various conceptions and explanations, and classify them as a function of whether they depict confirmation as a cognitive failure, a form of motivational prioritisation, or a pragmatic strategy. Then, we argue that confirmation has a specific social function, and propose that it is a fundamental mechanism that helps coping with competition. To corroborate this proposition, we present evidence from older and more recent research that tackled the question of the social determinants of reasoning.

\section{Confirmation and its interpretations}

The advent of the cognitive revolution in psychology (see Miller, 2003) focused the attention of psychological scientists on the cognitive processes responsible for behaviour, among which appear both reasoning and hypothesis testing (e.g., Gardner, 2008). Hypothesis testing, in particular, has been described as a fundamental process in human activity, as it intervenes for people from all walks of life, from lay inferences used to understand life events (e.g., Kruglanski, 1980) to formal reasoning in academic and scientific practices (e.g., Mitroff, 1974). However, as mentioned above, research has highlighted a systematic tendency towards confirmation in hypothesis testing (Caverni, Fabre, \& Gonzales, 1990). But, what is the problem with confirmation and why is it so interesting to psychologists?

Let us consider one of the classic studies of hypothesis testing. In his experiment, Wason (1960) asked his participants to guess the rule of composition of the 2-4-6 number string. Established by the experimenter, the rule was in this case "increasing numbers". The participants must think of a rule, that is, formulate a hypothesis, and propose triads of numbers to the experimenter, who informs them in return whether they are compatible with the rule to be discovered or not. Once the participants are convinced they have the correct rule, they communicate it to the experimenter who tells them if it is indeed the correct rule. This study revealed that participants most often propose number triads compatible with their hypothesis (e.g., 8-10-12 for the hypothesis "even numbers increasing in intervals of two"), believing that they can conclude that their hypothesis is correct if the experimenter judges their triad compatible with the rule to be discovered. However, the rule to be discovered is very general ("increasing numbers"), 
while the participants formulate hypotheses by trying to use all the information contained in the triad 2-4-6 (e.g., "even numbers increasing in intervals of two"); thus, when they propose confirmatory triads of their hypothesis (e.g., 8-10-12), participants always receive the answer that their triad is compatible (8-10-12 are indeed increasing numbers), but that they did not find the correct rule. It is by proposing a triad that is not compatible with their hypothesis (e.g., 3-5-11), thus by using disconfirmation, that participants can discover that the triad is nonetheless compatible (they are increasing numbers, but neither even, nor increasing in intervals of two), infer that the rule must, therefore, be more general than the one they have imagined, and approach the correct answer.

Thus, the problem with confirmation is that people systematically use a hypothesis-testing strategy that seems inadequate: To check the validity of their hypothesis using examples (triads) that describe it, while the most diagnostic strategy would be to test the plausibility of examples incompatible with this hypothesis. Confirmation is then interesting to psychologists because it is a phenomenon that questions human rationality. Indeed, it has been pointed out that laypeople do not reason according to the rules of formal logic, and not only in hypothesis testing (for a discussion, see Legrenzi \& Legrenzi, 1991).

Since the early work pioneered by Wason (1960), the tendency to use confirmation has been found in many domains of human cognition, from inductive reasoning (e.g., Gorman \& Gorman, 1984; Mynatt, Doherty, \& Tweney, 1977), to deductive reasoning (Evans, 1982; Wason, 1966). Moreover, the systematic use of confirmation was observed in several studies on the search for information about expectancies, from selecting and remembering information about one's personality (e.g., Mischel, Ebbesen, \& Zeiss, 1973) to selecting information and displaying behaviours as a function of person perception (e.g., Snyder \& Swann, 1978; see also Snyder, 1981), from confirmation of stereotypes (e.g., Darley \& Gross, 1983) to self-fulfilling prophecies (Jussim, 1986). Finally, a tendency to confirmation was found in countless other tasks and situations (see Evans, 1989; Holyoak \& Spellman, 1993; Pyszczynski \& Greenberg, 1987), even in theory-building in psychology (e.g., Greenwald, Pratkanis, Leippe, \& Baumgardner, 1986).

Three remarks are needed at this point to fully understand the nature of the confirmation phenomenon. First, confirmation can be due to a number of cognitive, motivational and social factors - as we will see in the following sections - but it is present in human inference at a certain baseline for sampling reasons. The sampling approach (Fiedler, 1996) explains that many judgment biases are due to the mere sampling of information. For example, self-other biases - the more positive evaluation of oneself as compared with others - can be explained by the amount of positive information about the self. We all know more about ourselves than about 
others, which makes self-related observations more readily available than other-related information. As positive behaviours are more frequent than negative behaviours, aggregation of information should result in extracting positivity to a larger extent for the self than for others. In other words, no biased processes, either cognitive or motivational, are necessary to explain the emergence of judgment biases, although of course, they may intervene to increase the prevalence of a phenomenon above the baseline. This approach implies that confirmation shares the emergent property of being sensitive to sampling with many other phenomena (see also Fiedler, 2008; Fiedler, Walther, \& Nickel, 1999; Le Mens \& Denrell, 2011), and that the explanatory mechanisms that we are going to review intervene in addition to this general process.

Second, confirmation does not always correspond to a suboptimal hypothesis-testing strategy. Laughlin, VanderStoep, and Hollingshead (1991), for example, pointed out that confirming evidence may be particularly useful during hypothesis formation, as it helps evaluate the plausibility of a hypothesis. Moreover, Klayman and Ha (1987) argued that many phenomena that are sometimes referred to as "confirmation bias" are in fact a form of what they call "positive test strategy", i.e., "a tendency to test cases that are expected (or known) to have the property of interest rather than those expected (or known) to lack that property" (p. 211). Confirmation should be used to refer to the tendency to retain a favoured hypothesis (Klayman, 1995). Positive test strategy can be useful in rule learning, concept identification and in environments where feedback is probabilistic. For instance, one may be concerned with a rare phenomenon (say, a disease) and formulate a hypothesis that corresponds to such a base rate; in this case, it is reasonable to conduct the test where one expects the phenomenon to occur (among people believed to be at risk) rather than the opposite. However, these authors also note that positive test strategy may lead to suboptimal results as it may conceal important falsifying instances, generate superfluous tests of necessity and overlook important tests of sufficiency (see also Klayman \& Ha, 1989)

Third, confirmation is not a uniform phenomenon. We have already noted that it may emerge in several domains of human cognition, but it should also be noted that there are several sorts of confirmation, at several stages of hypothesis development. As argued by Klayman (1995), confirmation can consist in (a) overconfidence in an initial belief, (b) searching for evidence in the data in a way that favours one's hypothesis, (c) interpreting available information so as to favour one's hypothesis, (d) insufficiently revising one's confidence in the initial hypothesis, and (e) failing to generate new hypotheses when doubts arise about one's hypothesis. However, this heterogeneity notwithstanding, "it is nevertheless possible to discern a 
general direction, namely a general tendency for people to believe too much in their favoured hypothesis" (Klayman, 1995, p. 385).

Several explanations have been proposed for this systematic appearance of confirmation, and there is no point in separating explanations that have arisen in the cognitive psychology literature from those that were provided by social psychologists. We decided instead to organise the main trends of this literature in terms of the mechanisms used to account for the emergence of confirmation, namely cognitive failure, motivational prioritisation, or a pragmatic strategy.

\section{Confirmation as cognitive failure}

The first category of explanations views confirmation as a failure of the cognitive system. Confirmation would be related to the existence of a more general positivity bias that is thought to be due to "cognitive difficulty in thinking about information that is essentially negative in its design" (Evans, 1989, p. 63). Accordingly, "[s]ubjects confirm, not because they want to, but because they cannot think of the way to falsify" (p. 42). In line with this idea, other authors consider that confirmation stems from a bias in information processing: Individuals focus on the first plausible hypothesis and do not consider the alternatives that could lead to the rule to be found (McDonald, 1990).

Along the same lines, several authors consider that the traditional tasks proposed to study reasoning - as for instance the 2-4-6 task presented above (Wason, 1960) - are too "difficult", i.e., they do not correspond to any psychological experience in real life. This trend considers that, on a daily basis, individuals do not possess a "mental logic" (Rips, 1994) that would allow them to solve a formal task as a logician would do (Legrenzi \& Legrenzi, 1991). By mental logic, we mean the capacity to use the rules of logic, without having studied them, as proposed in the Piagetian tradition (Inhelder \& Piaget, 1958). A similar criticism has been addressed by Oaksford and Chater (1994), who argued that analyses of human reasoning should move from normative to adaptive rationality (Anderson, 1990); in other words, rationality should be evaluated against the ability to adapt to one's environment and not against the rules of logic (see also Chater \& Oaksford, 1999; Hahn \& Oaksford, 2007).

The issue of difficulty has been addressed by research showing that the resolution of these problems can be improved if one articulates the task with a social dimension, in a sort of "social marking" (Doise \& Mugny, 1984). The first attempts in this direction consisted in associating a social connotation to Wason's selection task (Wason, 1966). In the original, abstract version of this task, participants were given four cards with letters on one side and numbers on the other side. Two cards were turned letter up 
and two number up (e.g., A-D-3-7). The participants were given a rule that applied to these cards: "if there is an A on one side of the card, then there is a 3 on the other side of the card", and asked to decide which cards, and only which cards, would need to be turned over in order to check whether the rule is true or false. This task aimed at studying how people test hypotheses of the type "if p, then q", and the logically correct answer is that only two cards should be turned over: A (if there is not a 3 on the other side, the rule is false) and 7 (if there is an A on the other side, the rule is false). Turning over the D card is useless, as the rule does not mention this letter, as is turning over the 3 card, as the rule does not prevent 3 from having a D on the other side. However, most participants of the original and follow-up experiments fail to select the correct cards, and instead select A and 3. This corresponds to a confirmation bias, in that participants look for cards potentially consistent with the rule (cards that should have an A and a 3), and fail to select the card that might disconfirm the rule (the 7 card), as noted by Wason and Johnson-Laird (1972).

The original selection task was then transformed by Griggs and Cox (1982) into the test of the hypothesis "if a person drinks beer, then he must be over eighteen" (which was a rule known to the participants). Falsification no longer corresponds here to the search for an abstract counter-example "not-q", but to the search for a breach in a social norm like "the person is under eighteen years old and drinks beer" (a case known and frequently observed by participants). And, indeed, the proportion of correct answers rose dramatically in this version. The perspective of Griggs and Cox (1982) is then to use social marking as a facilitator: Social experience is easily accessible through memory and people can actually apply a known situation to solve such a difficult task. Likewise, Johnson-Laird, Legrenzi and Legrenzi (1972) found a correct solution rate of $87.5 \%$ (instead of the usual percentage of just over $10 \%$ ) by embedding the selection task in a known postal control procedure.

Mental model theory offers a possible explanation for the difficulty in falsifying hypotheses (Johnson-Laird, 1983). When reasoning, people build mental models of the task at hand. However, due to limited cognitive resources, reasoners only build one mental model at a time (Legrenzi, Girotto, \& Johnson-Laird, 1993). This is a problem for the ability to use disconfirmation, as such a strategy requires the problem-solving participant to imagine a focal hypothesis and, at the same time, an alternative one; this requires participants to build two mental models. Thus, confirmation would be easier than disconfirmation because it requires them to build only one model.

Neglect of alternative hypotheses has also been identified as a central problem in other lines of research (e.g., Trope \& Mackie, 1987), in particular to the extent that it might produce a pseudodiagnosticity effect. 
Pseudodiagnosticity is the tendency to seek out confirmatory information consistent with the first available hypothesis, without envisioning alternative hypotheses. It is a misleading mechanism because it gives the impression that one is testing a hypothesis with relevant information, while one is, in fact, ignoring better options afforded by alternative hypotheses (e.g., Beyth-Marom \& Fischhoff, 1983; Maggi, Butera, Legrenzi, \& Mugny, 1998).

Although the research reviewed in this section suggests that confirmation is related to the inability to reason like logicians, some other research called this claim into question by showing that even extremely competent and educated people use confirmation when testing their hypotheses. Besides the anecdote about Albert Einstein, who allegedly declared that "he would reject the data before he would reject relativity theory" (Mahoney, 1979, p. 359), research on cognitive processes among scientists has shown that experts appear to be just as likely as laypeople to fall prey of confirmation (Mahoney, 1976). For instance, Mitroff (1974), who for 3 years studied a group of scientists working on the Apollo mission, concluded that "scientists were effectively involved with their ideas, were reluctant to part with them, and did everything in their power to confirm them" (p. 586). In sum, confirmation may be related to the difficulty inherent to hypothesis testing, and in particular hypothesis falsification, but this explanation cannot account for the pervasiveness of the phenomenon, even among scientists who have received formal training in logic and mathematics.

\section{Confirmation as motivational prioritisation}

The second category of explanations relies on the idea that the human motivational system prioritises motives in such a way that epistemic concerns related to truth and accuracy do not appear among one's priorities. For instance, people could be motivated to verify rather than falsify their hypotheses for self-consistency-related reasons, pertaining to "vanity and maintenance of the beliefs structure" (Evans, 1982, p. 42). A large number of studies have attempted to demonstrate the motivational hypothesis by studying how the prevalence of confirmation can be reduced by instructions that show the usefulness of disconfirmation, and therefore the participant's interest in using it. These studies have yielded rather variable results: While some showed the usefulness of the instructions (e.g., Tweney et al., 1980; Experiment 4, Gorman \& Gorman, 1984), others showed no improvement in the resolution of the task following disconfirmation instructions (e.g., Mynatt et al., 1977).

The theory of lay epistemics developed by Kruglanski (1980, 1989, 1990) presents a more comprehensive account of why people stop testing their hypotheses at some point and may be content with confirmatory 
evidence. This theory postulates that knowledge is formed in two phases, during which hypotheses are first generated and then evaluated (Kruglanski, 1990); evaluation can then lead to a new generation of hypotheses. Beyond the mechanisms of generation and evaluation, the theory of lay epistemics is particularly concerned with the motivational factors that determine both the initialisation and the termination of such processes. These factors depend on epistemic motivations, that is, the "motivations toward knowledge as object" (Kruglanski, 1990, p. 335) that are organised according to two variables. The first variable is the need to reach some closure (a conclusion as to a knowledge) versus the need to avoid closure (i.e., "closure seeking" vs. "closure avoiding"). The second variable pertains to the specificity versus nonspecificity of such closure (i.e., the importance for the individual of reaching either specific knowledge or any knowledge).

The need to reach nonspecific closure is particularly interesting for the question of hypothesis confirmation, as it incites the search for any response that may help avoid the risk of remaining under uncertainty. This is especially important in situations where a response must be provided within a limited amount of time, or when other factors increase evaluation apprehension (Kruglanski \& Freund, 1983). For example, situations in which prestige, status or competence are associated with having some knowledge (Hass, 1981) represent pervasive external pressures in everyday life - for instance in school or work settings - which implies that the need for nonspecific closure is likely to be highly prevalent.

The theory of lay epistemics distinguishes between two circumstances. First, the epistemic process is "frozen" when there is a correspondence between the knowledge one person has and the knowledge this person wants to achieve (Kruglanski \& Freund, 1983). This means that the generation of hypotheses is blocked and the individual will be insensitive to further information. Second, the epistemic process is "unfrozen" when the information one has is in conflict with the information one wants to achieve. This stimulates the generation of hypotheses and brings increased attention to the information that can be relevant to test them. The experiments carried out within this framework (Kruglanski, 1989) have shown that participants with a high need for nonspecific closure generate fewer hypotheses about the problem under evaluation, and show greater confidence in the hypotheses they have generated. Moreover, they form impressions on the basis of first information, and base judgments on stereotypes. This is not the case for participants with a need to avoid closure. These results are important because they show that confirmation may be a motivated form of closed-mindedness (Kruglanski, 2013) due to the dispositional or the situational need to reach some closure in the process of knowledge generation. 
Interestingly, work conducted on decision-making shows that confirmation may occur because of the very fact that knowledge has been generated. Frey's (1986) work on "selective exposure to information" revealed that once a decision is made, people tend to selectively seek out information likely to confirm that decision, and avoid any incongruent information. This mechanism is motivated by the need to avoid cognitive dissonance and reduces the probability that one will be exposed to new knowledge that may challenge one's decision. Further research from the same group showed that confirmatory information seeking also occurs in group decision-making (Frey \& Schulz-Hardt, 2001). Groups too prefer information that confirms past decisions, and this phenomenon is stronger in highly homogenous groups (Schulz-Hardt, Frey, Lüthgens, \& Moscovici, 2000). This result illustrates how - like in the case of need for closure - situational factors may be responsible for a general tendency in individuals and groups to prefer confirmatory evidence for one's choices.

\section{Confirmation as a pragmatic strategy}

The literature also offers several accounts of confirmation as a pragmatic strategy. For instance, Cheng and Holyoak (1985) developed a theory that incorporates the social experience acquired by the individual and the ability to use inference mechanisms. According to these authors, humans have developed a set of "pragmatic schemas," rules that are less abstract than truth tables in logic (since they are internalised by the experience of certain social situations), but nevertheless general enough to be applicable to all cases having the same form (which the authors call "domain-specific competences"). For example, resolving the task that requires checking the rule "if a person drinks beer, then he/she must be over eighteen" (see above) does not depend on knowledge of the particular case of underage people drinking beer, but on the fact that the participant can confront this specific situation to a set of rules that apply to the category of "permissions" (Cheng \& Holyoak, 1985; Light, Girotto, \& Legrenzi, 1990). Thus, according to this theory, the ability of people to solve reasoning problems, and to use disconfirmation, does not depend on the difficulty of the task, but rather on the extent to which linguistic and conversational features of the task allow them to apply a general pragmatic scheme. A similar point has been made by Cosmides (1989), although this author argues that the domain-specific competencies are determined by phylogenesis: If disconfirming evidence corresponds to cues that a cheater is trying to obtain a benefit without paying the cost, then reasoners are motivated to use disconfirmation to detect the cheater (see also Gigerenzer \& Hug, 1992; Tooby \& Cosmides, 1992). 
The pragmatics of conversation are also at the core of the "argumentative theory" (Mercier, 2016; Mercier \& Sperber, 2011). According to these authors, reasoning has evolved to allow conversation, as well as to help in the production and evaluation of arguments exchanged during communication. An important feature of this theory is that people are somehow biased and lazy during the production phase, but process information more effortfully and diagnostically when they evaluate arguments. In this respect, confirmation appears to be a feature of, and limited to, the production of arguments to convince others:

Conviction can hardly be achieved by providing interlocutors with arguments for their views or against that of the speaker. Argument production should thus be marked by a strong myside bias (or confirmation bias): people overwhelmingly produce arguments that support their point of view or attack that of the interlocutor. (Mercier, 2016, p. 690)

This is an important statement for the argument that we will develop later in this article: Confirmation may have a function in the regulation of social relations.

The idea that confirmation of hypotheses may have a pragmatic function in the regulation of social relations has also been defended by Leyens, Dardenne, Yzerbyt, Scaillet, and Snyder (1999). These authors explicitly addressed the social advantages of confirmation in general, while illustrating them in the domain of expectations in person perception. For example, in a study by Dardenne and Leyens (1995) participants displayed a preference for confirmatory information when testing a hypothesis about a personality trait of a person; however, this effect appeared mostly when participants were high in social skills and when the target person was high in status. The authors interpret this result as proof that confirmation can be a social skill, to the extent that it is important to be cautious (confirmatory) with a high-status person, and it is indeed what participants high in social skills do.

Leyens et al. (1999) thus adopt a non-normative approach in which the productions of reasoners are not compared to what should be expected according to formal logic, but rather focuses on what reasoners do as a function of the situational constraints. Since confirmation occurs in a wealth of situations and for a large number of individuals, these authors consider that it is the "default option" when testing hypotheses or expectations. While they recognise that several explanations may account for the systematic use of confirmation in hypothesis testing, they do not favour one explanation over the others; they rather claim that several explanations may interact. They also claim that confirmation is not necessarily a sign of laziness or failure of the cognitive system: They reviewed a sizeable body of work showing that people tend to 
memorise consistent evidence (e.g., Kunda, 1990), evaluate the amount of consistent evidence they possess (Ditto \& Lopez, 1992), and actively try to reconcile consistent and inconsistent information (Yzerbyt, Coull, \& Rocher, 1999). In conclusion, individuals are described as flexible perceivers who can use either confirmation or disconfirmation, either effortfully or effortlessly, depending on the demands of the social situation.

The role of situational constraints in social interactions is also at the core of Snyder and Stukas' (1999) appraisal of behavioural confirmation. A longstanding line of research has characterised behavioural confirmation as the process whereby a perceiver's beliefs about a target influences his or her behaviour when interacting with the target (Snyder, 1984). For example, if the perceiver believes that the target is kind, s/he will behave in a likeable manner, which will prompt a kind reaction from the target, which in turn will confirm the perceiver's belief. This work and that in the general area of self-fulfilling prophecies (Merton, 1948; Rosenthal, 1994) has been synthesised by Snyder and Stukas (1999) to propose a dynamic picture of confirmation in social relations:

The processes of confirmation and disconfirmation involve a complex intertwining of cognitive, motivational, and behavioral activities in social interaction - a dynamic intertwining in which features of perceivers and targets, of their motivation and their roles, and of their personal characteristics and their situational contexts are all integrated into scenarios of mutual and reciprocal influence on the processes and outcomes of social interaction. (p. 297)

\section{Confirmation as a coping response in competitive environments}

In the above literature review, we have documented how cognitive, motivational, pragmatic and social factors contribute to the emergence of the complex and multiform phenomenon of confirmation. We contend, however, that such a systematic and pervasive phenomenon as confirmation cannot be reduced to the failure of the cognitive or the motivational system, nor can it merely serve a generic pragmatic function. On the contrary, it must be a central mechanism of human activity serving an important and specific social function. In this article, we propose that confirmation is an adaptive mechanism that serves the function of coping with competitive situations. Indeed, because competition threatens one's feelings of competence, searching for consistent, self-confirmatory information may be reassuring. This general proposition will be broken down into three implications, of increasing levels of specification, that will be illustrated by a set of older and more recent studies from our research group: Confirmation occurs to a larger extent (1) when there is competition, (2) when competition is threatening, and (3) when competition threatens one's feelings of competence. 


\section{Implication 1: Confirmation occurs especially when there is competition}

If it is true that confirmation serves the function of coping with competition, it should be found that confirmation occurs especially in competitive environments.

\section{Confirmation in competitive vs. cooperative environments}

The first study that will be presented addresses the question of whether confirmation is more likely to occur in competitive than in cooperative environments. In this study (Toma \& Butera, 2009, Experiment 1), 90 French psychology students were asked to solve a mystery (a road accident) in groups of three freely interacting participants. Participants read a set of clues and discussed as a group of three people in order to find the best solution (see below). Competition was induced through the structural features of the group work: The group was asked to discuss the case together and was told that

although in group decision situations members generally make a joint decision, it is often important to be the first in the group to propose a solution. Thus, their goal was to outperform the others by being the first in the group to offer the best solution. (Toma \& Butera, 2009, p. 797)

This competition condition was contrasted with a cooperation condition in which participants were asked to reach a joint decision that they would have to announce collectively when they all agreed with it. In other words, competition and cooperation were manipulated by creating either negative or positive goal interdependence, respectively (Deutsch, 1973).

The information about the accident was distributed following a "hiddenprofile" scheme (Stasser \& Titus, 1985): Groups were given two sets of information (see Table 1), one that was shared across the three group members, and one that was unshared (i.e., unique to each group member). Unshared pieces of information were designed to point to a certain character as the guilty person in the scenario ( Mr X, Mrs Y or Mr Z), and each piece was distributed to a different group member (i.e., participant $\mathrm{A}$ received the unshared information suggesting that the culprit was $\mathrm{Mr} \mathrm{X}$; participant $B$ received the unshared information suggesting that the culprit was Mrs $\mathrm{Y}, \ldots)$. And, indeed, pilot testing showed that participants endorsed the initial preference suggested in the unshared information by choosing the intended guilty person (Toma \& Butera, 2009, appendix). The important question is whether participants use the unshared information to disconfirm their initial preference and to reach the correct solution. In other words, will participants remain stuck to their initial preferences (and will they tend to confirm them), or will they be able to use the available disconfirming information? 
Table 1. The hidden profile task (adapted from Toma \& Butera, 2009, Personality and Social Psychology Bulletin. Copyright by Sage).

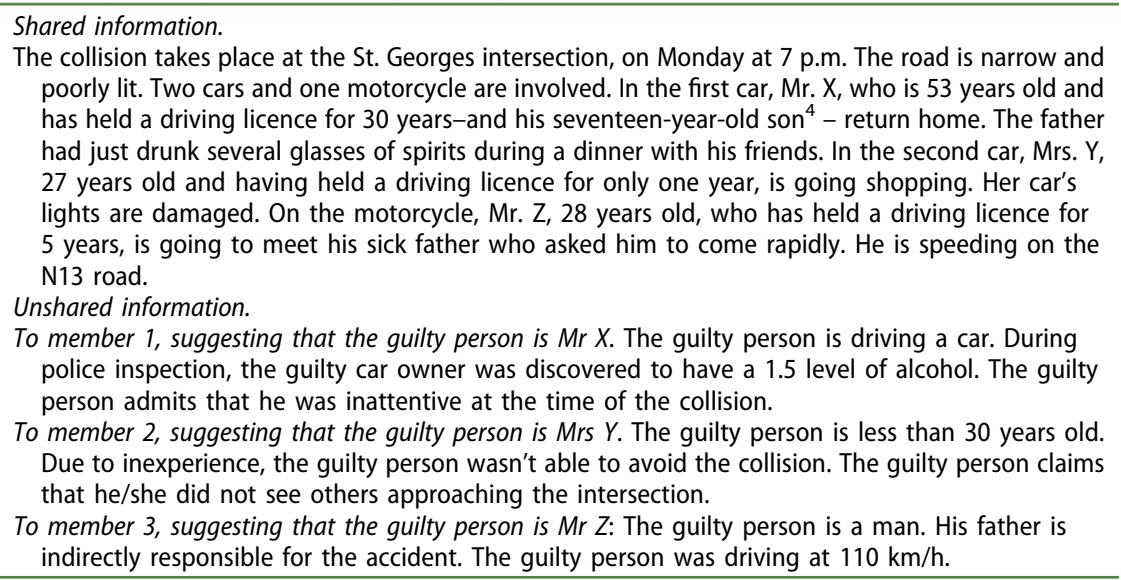

As illustrated in Figure 1, participants in the competition condition (15 groups) engaged in less disconfirmation than those in the cooperation condition (15 groups); that is, they were less likely to use the available information to test the limits of their initial preference, which therefore remained unquestioned. This result was replicated in the second experiment of the same article (also shown in Figure 1): Again, participants in the competition condition (14 groups) engaged in less disconfirmation than those in the cooperation condition (14 groups). To summarise, these first two experiments suggest that participants in a competitive (vs. cooperative) group structure were less susceptible to question their initial preference. This is an important preliminary piece of the puzzle, to the extent that confirmation was described as the inability to consider alternative hypotheses; these results show that the problem might not be the participant's inability to disconfirm but rather disconfirmation's lack of functionality in a negatively (vs. positively) interdependent group structure.

\section{Confirmation or mere differentiation?}

One possible alternative interpretation of the results presented above is that confirmation may be a way to assert one's own specific position in situations where diversity is present. Competition would then be merely an accentuating factor that makes it clear that differences in points of view, or solutions, are important. This interpretation is plausible and in line with the work on differentiation by Lemaine (1974), which has revealed that people are motivated to feel unique. One way to achieve this goal is to express judgments that 


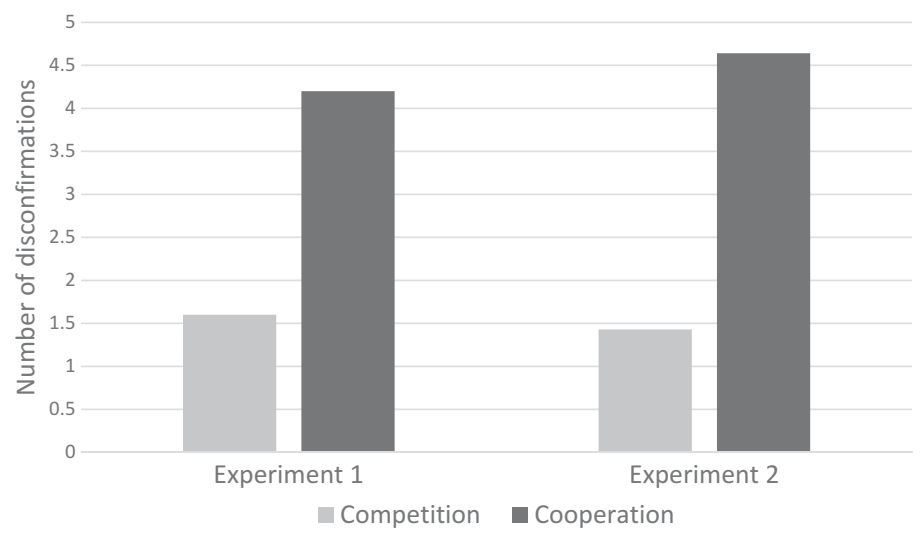

Figure 1. Number of disconfirmations (statements in which a member ruled out any initial preference) per condition, in Experiments 1 and 2 (based on Toma \& Butera, 2009). The main effect of cooperation-competition was $F(1,28)=6.76, p<.05$, $\eta_{\mathrm{p}}{ }^{2}=.19$ in Experiment 1 , and $F(1,26)=12.74, p<.001, \eta_{\mathrm{p}}{ }^{2}=.33$ in Experiment 2 .

make differences with others apparent (Lemaine, 1975). Thus, is confirmation driven by competition or simply by dissent?

In two experiments $(N=80$ and $N=120)$, Toma, Gilles, and Butera (2013a) asked French and Belgian university students to work on the same car-accident case described in the previous section, but this time without real interaction: Thanks to a role-play procedure, they were asked to imagine that they were police inspectors required to interact with two other team members in the case. Competition and cooperation were again induced through negative and positive interdependence (a promising promotion for one of them vs. for the team). In Experiment 2, a control condition without goal instructions was also introduced, but we will not report it here in order to facilitate the comparison between the two experiments. A second independent variable was then introduced: In the dissent condition, participants were given the hypothesis formulated by the two other group members (Mrs Y and Mr Z; the participant was always oriented to think that $\mathrm{Mr} X$ was responsible for the accident), whereas in the no dissent condition, the others' solutions were not provided.

In this study, confirmation was operationalised through a measure of "preference for consistent information" (Greitemeyer \& Schulz-Hardt, 2003): After having studied the case, participants were given six supplementary pieces of information, three of them consistent with their initial preference and three of them inconsistent. As their initial preference was $\mathrm{Mr} \mathrm{X}$, an example of consistent information was that "the person responsible for the accident is a man", whereas an example of inconsistent information was that "the person responsible for the accident is less than 30 years old" ( $\mathrm{Mr} \mathrm{X}$ was 53 years old). 
Participants were then asked to rate on a 9-point scale the extent to which each of these items was important for reaching the optimal decision. Preference for consistent information consisted of a score in which the ratings of the inconsistent information were subtracted from the ratings of the consistent information; this score indicates the degree to which participants evaluated information so as to confirm their initial preference (Toma et al., 2013a).

In both experiments, the analyses revealed an interaction between competition (vs. cooperation) and dissent (vs. no dissent): Participants manifested a stronger preference for confirmatory items under competition than under cooperation, to the extent that their initial solution was different (vs. not) from that of the other two fictitious members. Both experiments showed that when there was dissent, the preference score was positive in the competition condition (i.e., a preference for consistent over inconsistent items), whereas the score was negative in the cooperation condition (i.e., which refers to a preference for inconsistent over consistent items). This suggests that participants' behaviour is logically rational in the cooperative condition, as they use disconfirmation as a diagnostic strategy that leads to the elimination of sub-optimal hypotheses. When participants compete with the other team members, they prefer confirmatory items, even if their diagnostic value is lower.

In this study, the authors also coded the degree to which - beyond the expressed preference - the final choice of participants reflected a confirmatory decision. The authors coded whether the participants' final decision identified the same culprit that they had picked before receiving the supplementary information. As can be seen in Figure 2, the results again revealed an interaction, showing a stronger confirmatory behaviour in competitive (vs. cooperative) settings, a difference that was larger when dissent was present (vs. absent). Thus, these two experiments allow us to understand that dissent per se is not responsible for increased use of confirmation: Dissent resulted in a stronger preference for confirmation and more confirmatory decisions when participants were in competition, whereas dissent in a cooperative context showed that the initial suboptimal decision needed to be abandoned. Competition leads to confirmation when people need to assert the superiority of their own solution over those of their competitors.

\section{Confirmation and self-other judgments}

It may be argued that confirmation is a pervasive phenomenon because it is an instance of a more general and equally pervasive phenomenon known as self-other bias, whereby judgments regarding the self are more positive than those regarding others (Brown, 1986). This idea would amount to the claim that people stick to their own hypotheses because of a general tendency to 


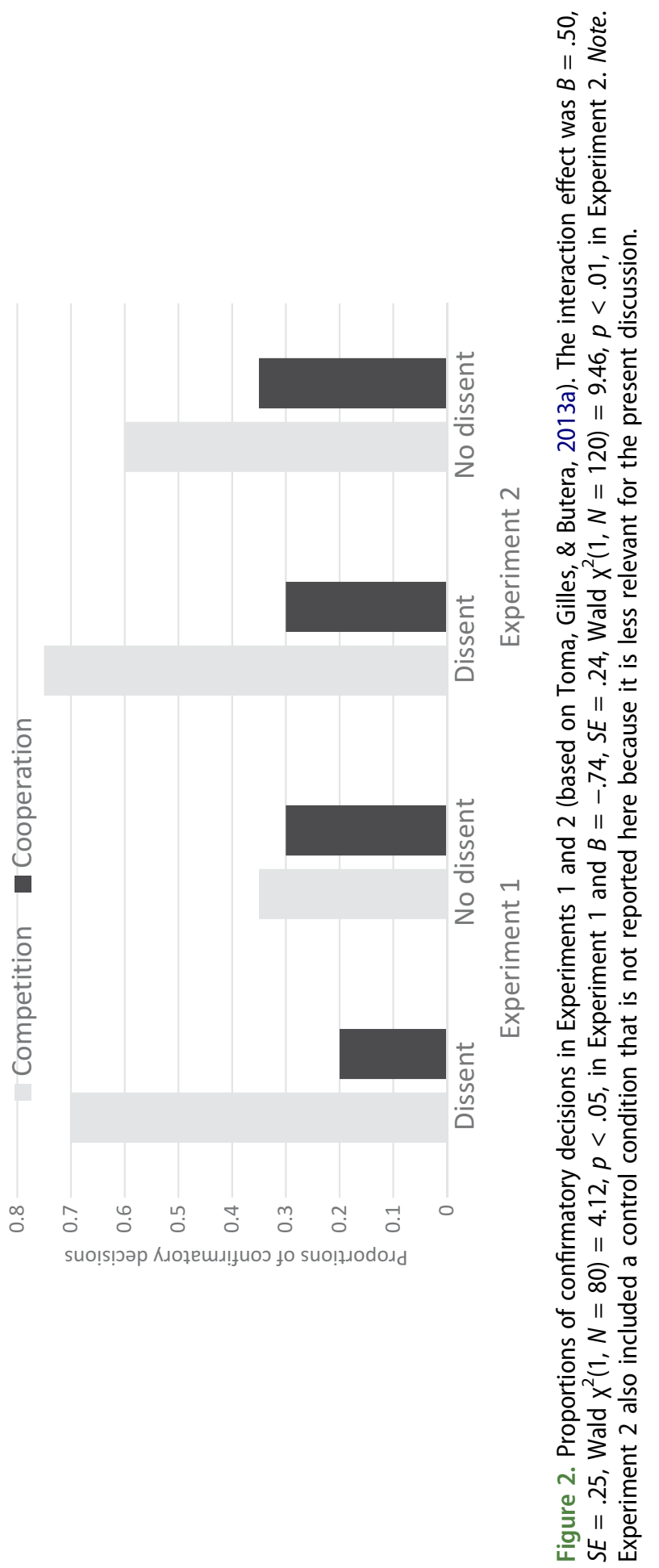


favour one's own ideas. The results of Toma, Bry and Butera's (2013b) study allow us to study the generic pervasiveness versus situational emergence of these two phenomena.

The procedure of this experiment introduced the same task used in Toma et al. (2013a). Participants, 50 Swiss university students, were again asked to imagine solving an accident case in a team of police officers who would be promoted, in the case of success, either individually (competition) or as a team (cooperation). This time, however, they were asked to rate, on a 9-point scale, the importance of nine, instead of six, supplementary pieces of information, in order to assess the participants' judgment toward (a) three items referring to consistent and (b) three items referring to inconsistent information that the team members possess, but also (c) three items related to information they had from the beginning (own information). The latter information was provided to study the "ownership bias" (Chernyshenko, Miner, Baumann, \& Sniezek, 2003; see also the "myside bias", Stanovich, West, \& Toplak, 2013), a self-other bias whereby group members value their own information more than that of the others. As in the research presented above, the results showed that competition led to more positive evaluation of confirmatory information and less positive evaluation of disconfirmatory information than cooperation. Moreover, participants also rated their own information more positively when working under competition than cooperation, $\eta_{\mathrm{p}}{ }^{2}=.25$ (see Table 2). It then appears that preference for confirmation and preference for own information are two distinct phenomena that vary as a function of the negative versus positive interdependence that binds group members. Thus, preference for confirmation and preference for own information occur when people know that they will be assessed via a competitive comparison with other group members.

\section{Competitive structures, norms and goals}

In the above work, competition was structurally induced through negative interdependence (Toma \& Butera, 2015), but it is reasonable to assume that other factors inducing or implying competition should play the same role. This is an important assumption as it would explain why confirmation is so often found in laboratory experiments, where competition can be prompted by the presence of co-actors or even mere normative evaluation (an experiment is evaluative in nature).

Table 2. Mean evaluation of own and other's information in cooperation and competition (Adapted from Toma et al., 2013b). Standard deviations in parentheses.

\begin{tabular}{lccc}
\hline & Own & Other's consistent & Other's inconsistent \\
\hline Cooperation & $6.23(1.25)$ & $4.57(1.74)$ & $5.75(1.54)$ \\
Competition & $7.33(1.36)$ & $6.00(1.76)$ & $4.76(1.58)$ \\
\hline
\end{tabular}


One important source of competition is the presence of a graded assessment in a task. Indeed, from the beginning of school life, pupils understand that grades come with two important features: They make performance visible and they afford an easy tool for social comparison and differentiation (Pulfrey, Darnon, \& Butera, 2013). Pupils, then students, then workers thus realise that a high grade is a scarce reward and that their classmates or workmates are competitors in the race to obtain such a reward. This explains why grades are often conceived of as norm-based (or normative) assessment (Pulfrey, Buchs, \& Butera, 2011). In a set of two experiments, Hayek, Toma, Oberlé, and Butera (2015) studied the relation between grading and confirmation. They used the same research paradigm set out by Toma et al. (2013a) and measured the preference for confirmatory information, which in this paradigm is computed by subtracting consistent from inconsistent information. In both experiments $(N=162, N=96$, both with Swiss students), they contrasted a condition where participants expected a grade with other conditions without grades. They showed that preference for confirmatory information was higher in the graded condition. In other words, confirmation rises when a competitive environment is hinted by grades, an evaluative tool that is most often associated with the situational need to distinguish oneself positively in comparison with others.

The dispositional need to distinguish oneself positively in comparison with others has also been found to be associated with some forms of confirmation. Darnon, Muller, Schrager, Pannuzzo, and Butera (2006) measured a set of achievement goals: Mastery goals (the desire to learn) and performance goals (the desire to outperform others ${ }^{1}$; Elliot \& McGregor, 2001). The authors asked their participants, 51 French psychology students, to imagine a debate with a disagreeing partner, and then assessed the extent to which participants intended to regulate such a disagreement in an epistemic way (focusing on the knowledge involved in the task) and in a relational way (trying to show that one was right and the partner was wrong; Butera, Darnon, \& Mugny, 2011). Participants indicated to what extent, from 1 to 7 , when disagreement occurred they tried to "think about the text again in order to understand better", "examine the conditions under which each point of view could help you understand", "think of a solution that could integrate both points of view" (epistemic regulation), "resist by maintaining your initial position", "show your partner was wrong", and "show you were right" (relational regulation). The

\footnotetext{
${ }^{1}$ It is important to note that performance goals have been divided into performance-approach goals (the desire to outperform others) and performance-avoidance goals (the desire not to be outperformed by others; e.g., Elliot \& McGregor, 2001). In this article, we focus on competition and competitive goals; we are therefore concerned with performance-approach goals. However, to increase readability and fluency, we will use the term "performance goals" to refer to "performance-approach goals", i.e., competitive goals.
} 
measure of relational regulation is particularly interesting here because it captures what confirmation entails: One's hypothesis is right and if a conflicting hypothesis is formulated, this must be wrong. Results revealed a correlation showing that the higher the competitive goals of outperforming others, the stronger the will to regulate the dissent in relational way (i.e., in a self-confirmatory way), $r(51)=.51$.

A few years later, Sommet et al. (2014, Study 1) found the same relationship, but this time with a behavioural measure. In this study, 36 Swiss educational sciences students worked in dyads, and were asked to debate human memory, with each member reading a different text: One text referred to the primacy effect (the first elements of a series are better remembered than the following ones), whereas the other text referred to the recency effect (the last elements of a series are better remembered than the previous ones). Although both effects exist, they seem contradictory, and a debate with these two standpoints is bound to be conflictual. At the end of the debate, participants were asked to evaluate four graphs on a 7 point scale:

The graphs represented four possible relationships between 'the position of a word' and 'the probability of recall': (1) A decreasing curve (corresponding to the primacy effect); (2) An increasing curve (corresponding to the recency effect); (3) A U-shaped curve (corresponding to the serial position effect); and (4) An inverse U-shaped curve (corresponding to an incorrect alternative answer). (p. 138)

The results showed that the higher the participants' scores on performance goals, the more positive the evaluation of the model corresponding to their initial position, $\beta=.43$ : A decreasing curve if they had studied the primacy effect and an increasing curve if they had studied the recency effect. In other words, self-set competitive goals predicted a confirmatory choice.

\section{Summary}

We proposed that confirmation is an adaptive mechanism allowing people to cope with their threatened feelings of competence in case of competition. In this section, we evaluated the first implication of this proposition, namely that if the proposition is true, confirmation should appear to a larger extent in competitive settings. The studies presented above provide strong support for this implication, as all of them showed that confirmation was stronger when participants worked in a group where members were tied by negative rather than positive goal interdependence. This was true when participants actually worked in a group and when they imagined working in a team. It was true with different measures of confirmation, be they the lack of use of information that may disconfirm one's initial decision, the preference for information that was consistent with one's 
initial decision, or final decisions that were identical to the initial ones. And the effect generalised to competition induced by cultural norms - the presence of graded evaluation - and self-set competitive goals. If confirmation is indeed a pervasive phenomenon, it might be because competition is pervasive, at least in capitalist countries (Schwartz, 2007).

\section{Implication 2: Confirmation occurs especially when competition is threatening}

If it is true that confirmation has the function of helping us to cope with competition, it should be found that confirmation occurs especially when competition is threatening. Competition is not always threatening, only when one is likely to lose. Indeed, competition is a source of stress that can be appraised in two different ways, either as a challenge or as a threat (e.g., Tomaka, Blascovich, Kelsey, \& Leitten, 1993). Appraisal will follow the challenge path when one expects that available resources (material or symbolic) will exceed the demands (in the case of competition, when one expects to win). Conversely, appraisal will follow the threat path when one expects that the demands will exceed available resources (e.g., when one expects to lose). Therefore, when people are involved in a confrontation in which they are weaker and may expect to lose, they are likely to feel threatened and confirmation should appear to a greater extent than when people do not feel threatened.

Before we move forward and present the relevant research, a question remains: What is threat? Butera and Darnon (2017) have recently discussed this question that often arises in research dealing with self-evaluation: Drawing on research by Tesser (1988), Steele (1988), and Muller and Butera (2007), they explained that threat is the outcome of failure to reach the expected or hoped-for self-evaluation. This conception of threat is particularly relevant for the present discussion of the threatening potential of competition when some inferiority is expected: Competition with upward sources signals a high probability of losing and is therefore threatening. This is consistent with Muller and Fayant's (2010) review showing that upward comparison with a dissimilar or hard-to-reach source is indeed threatening for self-esteem, social desirability, self-efficacy and other important features of the self. This conception of threat is also interesting because it implies that the elicitation of threat may be measured not only through physiological measures (e.g., Blascovich, Mendes, Hunter, Lickel, \& KowaiBell, 2001), but also through the regulatory mechanisms that threat produces (Tesser, Millar, \& Moore, 1988). Confirmation, as argued in the present article, is one such mechanism. 


\section{Threatening influence sources}

Let us begin with the case of a social comparison that is threatening because one is confronted with a majority. In a series of three experiments ( $N=93, N=156, N=155)$, Legrenzi, Butera, Mugny, and Pérez (1991), Butera and Mugny (1992), and Butera, Mugny, Legrenzi, and Pérez (1996) asked their participants (Swiss university and high-school students) to solve a set of inductive reasoning problems akin to the 2-4-6 task presented above (Wason, 1960). As in the original task, after they were given the triad 2-4-6, participants were to (a) formulate a hypothesis as per the rule that generated this triad and (b) test this hypothesis by proposing a new triad. Remember, that in this task people display a strong tendency to use confirmation (Butera \& Mugny, 2001). The task devised in these three experiments, however, was embedded in a social influence setting, to study if hypothesis confirmation appeared systematically or if it appeared as a function of the influence source. Before writing down their answer (i.e., formulating a hypothesis and testing it), participants were informed about the answer given by an influence source. Specifically, they were given the answer allegedly proposed by a majority or a minority of previous participants. This manipulation of numerical support is particularly relevant to the question of whether confirmation occurs especially when people are confronted with a threatening source. In an influential article, Nemeth (1986) argued and showed that being confronted to a majority is particularly threatening because people hold heuristic beliefs regarding numerical support, in particular, that majorities are generally right (see also De Vries, De Dreu, Gordijn, \& Schuurman, 1996), which is not the case if the influence source is a minority.

In Figure 3 we report the mean proportion of confirmation in hypothesis testing in the aforementioned three experiments. It is the mean proportion because in each experiment participants had to solve two problems of the same type. Although these experiments also included other independent variables (see the original articles), we only report the difference between the majority and minority conditions, which are the focus in this section. Results showed that the proportion of confirmatory testing was higher when participants were confronted with a majority than a minority, a difference that was significant in the three experiments. In sum, a more threatening influence source (a majority), elicited a higher proportion of confirmation than a less threatening source (a minority). 


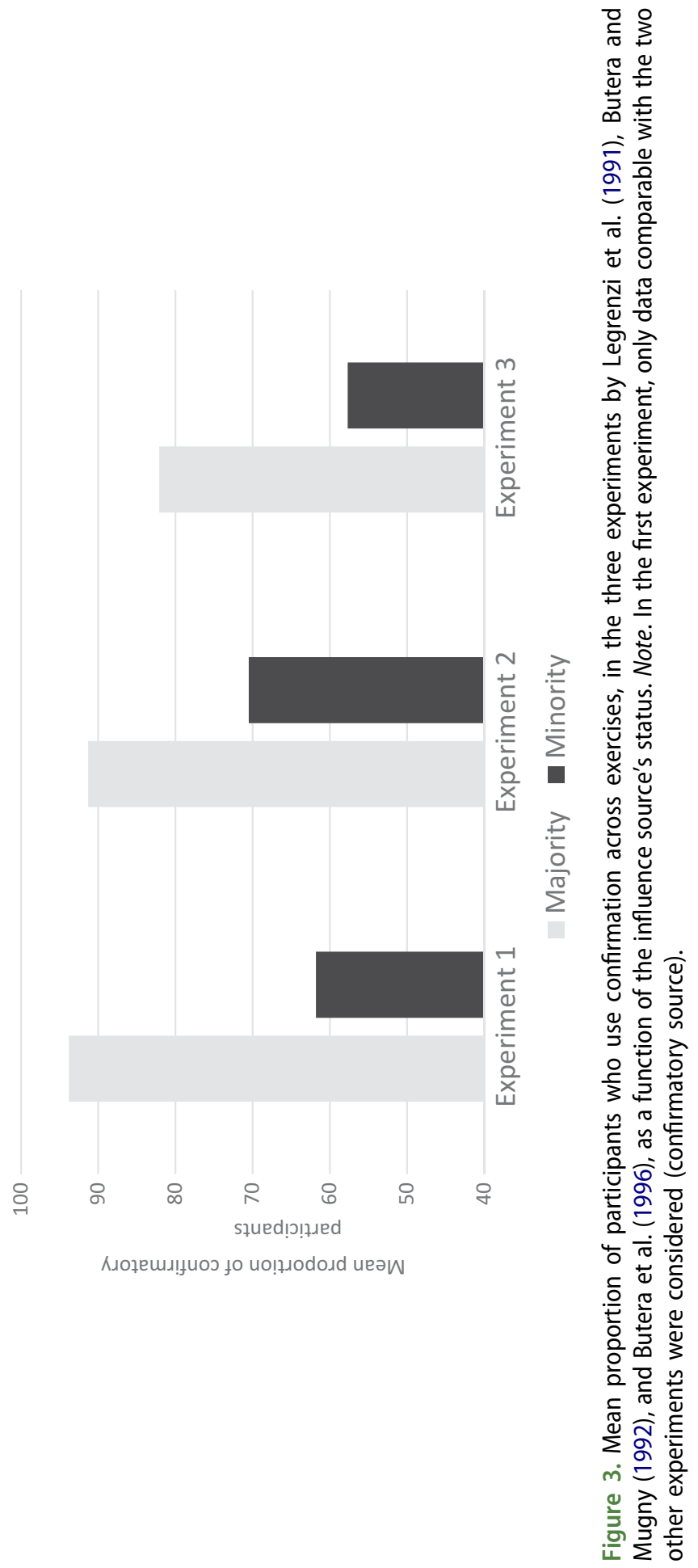




\section{Threatening social comparison}

Another case of threatening confrontation is when competition takes place with a superior other. Sommet, Darnon and Butera (2015, Experiment 1) measured their participants' competitive goals (with the three items of the performance goals scale, as in Sommet et al., 2014, presented above) and then provided their participants with a text on either the primacy or the recency effect. The study was conducted on the Internet: The 139 participants, all Swiss university students, were contacted by email and invited to participate in an online study on collaborative e-learning. As in Sommet et al. (2014), they received the seemingly contradictory answer of a bogus student who explained the opposite effect (respectively, either the recency or the primacy effect). Importantly, the other student's status was manipulated to be either the same as the participant (same grade level) or superior (higher grade level). Finally, participants were given a series of items to assess how they regulated the conflict with the partner, among which three self-confirmation items: To what extent "did you try to show you were right?", "did you try to show your partner was wrong?", and "did you try to resist by maintaining your initial position?", on a 7-point scale The results showed that the performance goals score positively predicted confirmatory conflict regulation when the partner was higher, but not when similar, in status (see Figure 4). Thus, self-set competitive goals resulted in higher selfconfirmation especially when participants were led to compare themselves with a superior partner.

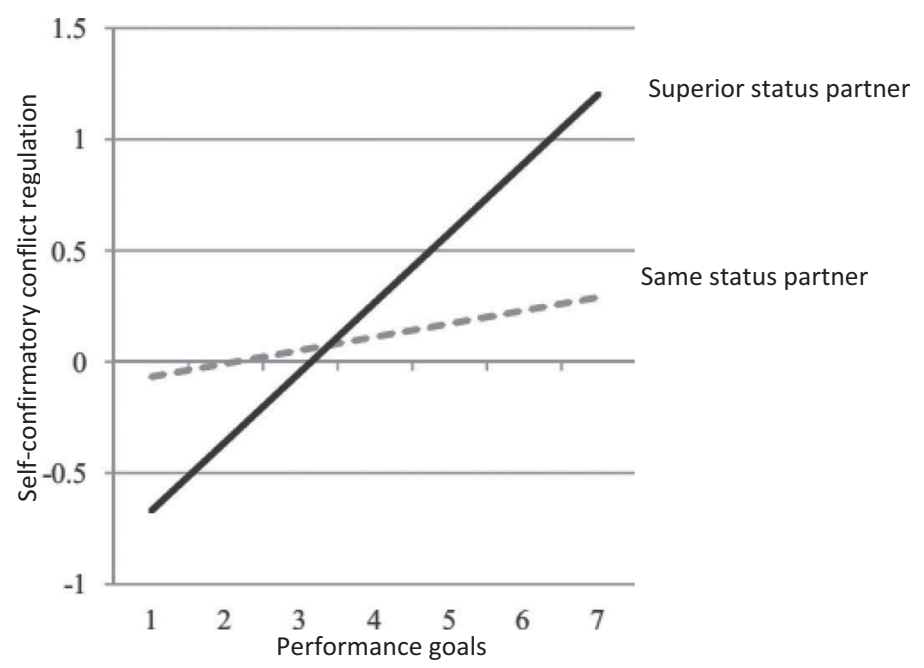

Figure 4. Confirmatory conflict regulation as a function of self-set performance goals (From Sommet et al., 2015, Experiment 1. Journal of Educational Psychology. Copyright by the American Psychological Association). The interaction effect was, $\beta=.19, F(1$, 129) $=4.38, p<.04, \eta_{p}^{2}=.03$. 
In another study with 73 French vocational school students, Sommet et al. (2015, Study 2) tested whether the same effect could be obtained with manipulated competitive goals and with a measure of behavioural confirmation. They first induced competitive goals, namely performance goals through instructions. Then, they provided their participants with a text on either the primacy or the recency effect, and with the alleged opinion of another student who explained the opposite effect. The other student's status was again manipulated to be either the same or superior. Finally, the participants had to rate two curves that corresponded to the participant's theory (either recency or primacy) and to the other student's theory (as in Sommet et al., 2014, presented above). A preference for the confirmatory model was then computed, by subtracting the evaluation of the model (the curve) patterning the other student's theory from the evaluation of the model patterning the participant's. The results showed that if performance goals had been induced the preference for the confirmatory model was higher when confronted to a superior rather than a same-level partner. These results bring convergent support to implication 2, in that they show that confirmation increases with the presence of situational competitive goals and confrontation with a threatening other.

\section{Reducing threat}

We argued that the presence of a superior other is threatening in a competitive situation because it prompts the possibility of losing. If this is true, when such a possibility is removed, threat should be reduced and the use of confirmation limited. This is what Butera and Mugny (2001) found. In their final experiment, with 111 Swiss high-school students, these authors asked the participants to solve an inductive reasoning task, while being confronted with a disagreeing other who was presented as high in competence. Two variables were manipulated. The first induced either negative interdependence of evaluation or independence1995, thereby creating vs. defusing competition. The second variable manipulated complementarity of points of view. Half of the participants were confronted with a task that made salient vs. not the usefulness of complementarity of points of view (Huguet, Mugny, \& Pérez, 1991): Participants were shown that people benefit from trying to integrate seemingly inconsistent points of view, because reality may be more complex than it seems. The dependent variable assessed to what extent the participant's hypothesis was tested with confirmatory or disconfirmatory examples.

Let us discuss to what extent the results of this experiment enlighten the question of the reduction of threat and confirmation. The main effect of negative interdependence of evaluation vs. independence revealed a lower proportion of confirmation responses when competition was defused by independence. This is consistent with our assumption, in that it is less 
threatening to disagree with a competent partner when there is not (vs. there is) competition; and indeed it is in this situation that confirmation is reduced. The main effect of complementarity (vs. not) of points of view revealed a lower proportion of confirmation when it was made clear that people benefit from integrating seemingly inconsistent points of view. This is also consistent with our assumption, in that it is less threatening to disagree with a competent partner when there is (vs. is not) the possibility that both points of view are part of a more complex reality. Thus, removing the possibility of losing, or reducing its relevance, made it possible to reduce the occurrence of confirmation.

\section{Summary}

In this section, we evaluated the second implication of our general proposition, namely that, if it is true that confirmation is an adaptive mechanism intended to help coping with threatened feelings of competence in case of competition, then confirmation should occur to a larger extent when competition is threatening. The studies presented above bring convergent support to this implication. Confirmation was higher when social comparison was unfavourable, either because participants were confronted with a majority or because competition took place with a superior other.

It is important to note that social comparison does not need to provide the certainty of losing in order to be threatening: Research has shown that merely doubting one's standing is sufficient (Muller \& Butera, 2007), which might explain why confirmation has occurred for decades when participants worked on reasoning task in which social comparison was not explicitly manipulated but in which there was the possibility of not meeting some standard.

It is also important to note that threat comes from social comparison with a potential competitor in the social space (a schoolmate, a colleague, a fellow participant in an experiment, etc.). This note is important because one might argue that, as reported above, Cosmides (1989) has shown that when participants try to detect cheaters, the disconfirmation rate increases, and cheaters are arguably potential competitors. However, in the work conducted by Cosmides (1989), cheaters are characters in a vignette. In other words, they are part of the task and not a social comparison target. This remark also applies to research showing that distrust increases the use of disconfirmatory strategies in rule discovery (Mayo, 2015). Indeed, it could be argued that competitors are sources of distrust to the extent that they hold negatively interdependent goals in relation to the reasoner. However, in this line of research distrust was unrelated to the reasoning task: It was either measured by a scale explicitly unrelated to the reasoning task (Mayo, Alfasi, \& Schwarz, 2014, Study 1), or primed by an untrustworthy face explicitly unrelated to the reasoning task (Mayo et al., 2014, 
Study 2), or primed by fishy smells (Lee, Kim, \& Schwarz, 2015). Again, the source of distrust was not a social comparison target.

\section{Implication 3: Confirmation occurs especially when one's competence is threatened}

If it is true that confirmation has the function of coping with competition, it should be found that confirmation occurs especially when competition is threatening for one's feelings of competence. Why do we need to differentiate implication 2 and implication 3? Is it not sufficient to state that confirmation occurs when competition is threatening (implication 2)? What is the added value of implication 3 and the specification that confirmation occurs when competition threatens one's competence? We believe that this distinction is important, based on an abundant literature that points to the various areas of human life that can be threatened, besides competence.

First, threat may arise in areas of human life that are not directly concerned with self-concept, like for instance safety (e.g., Lynch, Plant, \& Ryan, 2005) or existential concerns (Greenberg, Solomon, \& Pyszczynski, 1997). Second, some authors have studied threat to the self without further specifications (e.g., Andersen \& Chen, 2002), whereas others have specified which self-related construct was concerned by threat, as in work on control threats (e.g., Kay, Gaucher, McGregor, \& Nash, 2010), self-certainty threats (e.g., Hogg \& Mullin, 1999), or threats to meaning (e.g., Heine, Proulx, \& Vohs, 2006). Third, some authors have pointed out that competence is a fundamental human need, but so are relatedness and autonomy (Ryan \& Deci, 2000a), two human needs that can also be threatened (Ryan \& Deci, 2000b). In sum, it appears important to discuss competence threat as a distinct construct.

\section{Competence threat}

Let us start by considering how competence may be threatened by competition. Self-evaluation threat theory (Muller \& Butera, 2007) argues that some threat to self-evaluation occurs whenever one's competence does not meet the standards. Competence assessment is one of the most fundamental motivations in human activity, and social comparison is the tool that affords information about standards that may help in self-evaluation (Festinger, 1954). Standards may be persons, groups, reputations, rankings ... in sum, any clue about levels of competence that may afford comparative information (Butera \& Darnon, 2017). When such comparative information reveals that one's competence is (or may be) below some relevant standard, self-evaluation is threatened. Threat to self-evaluation manifests itself by a focusing effect, that is, more attention is allocated to central cues than to peripheral cues (Muller \& Butera, 2007). Social comparison per se consumes attentional resources and creates a distraction that 
limits attention to the central features of a task. Going further, Muller and Butera (2007) showed that this is the case when social comparison does not allow a person to fulfil their motivation to achieve a positive evaluation of their competence. In short, self-evaluation threat leads one to only consider the most central, salient, relevant features of a task. From then on, it is arguable that confirmation is a form of focusing effect, as confirmation limits hypothesis testing to the features present in the hypothesis, without considering alternative states of reality. In this section, we propose that the possibility of losing in a competition threatens one's feelings of competence, which results in confirmation.

\section{Competence threat and confirmation}

Butera and Mugny (1995) conducted a study that helps in the current discussion, as it manipulated the presence-absence of competition and measured both competence threat and confirmation of hypotheses. In this experiment, 69 Swiss high-school students were presented with a series of inductive reasoning problems, in which they had to test a hypothesis. As in the study by Butera et al. (1996) presented above, participants were also informed about the test conducted by an influence source before being able to proceed with their own answer. Moreover, once they began the task, participants were asked to evaluate their competence and that of the other on a series of four traits (competence, qualification, skill, expertise). This evaluation was either independent (participants evaluated each trait on separate 100-point scales for oneself and for the other) or negatively interdependent (participants evaluated each trait for oneself and for the other, but the total had to amount to $100 \%$ ). The latter induction puts the participant and the other in a competitive relationship (i.e., what is given to the other is detracted from oneself). Finally, participants could go on and test their hypothesis.

Inspection of the points distributed to oneself and the other shows clear evidence that competition induced competence threat: In the independence condition, participants attributed a comparable number of points to oneself and the other (slightly more to oneself, on average around 50 vs. 44 , see Butera \& Mugny, 1995), whereas in the negative interdependence condition participants showed a strongly asymmetrical distribution of points, claiming a clear and indisputable superiority of oneself over the other (on average around 71 vs. 29; see Figure 5). This is an interesting result as it corresponds to establishing an extremely favourable downward comparison with the other, a phenomenon that early research on social comparison clearly associated with the need to cope with threat (Wills, 1981). Thus, the competitive structure of the negative interdependence condition resulted in a distribution of points that reveals the emergence of a competence threat. The results also showed that in the negative interdependence condition participants used confirmation to test their hypotheses to a larger extent 


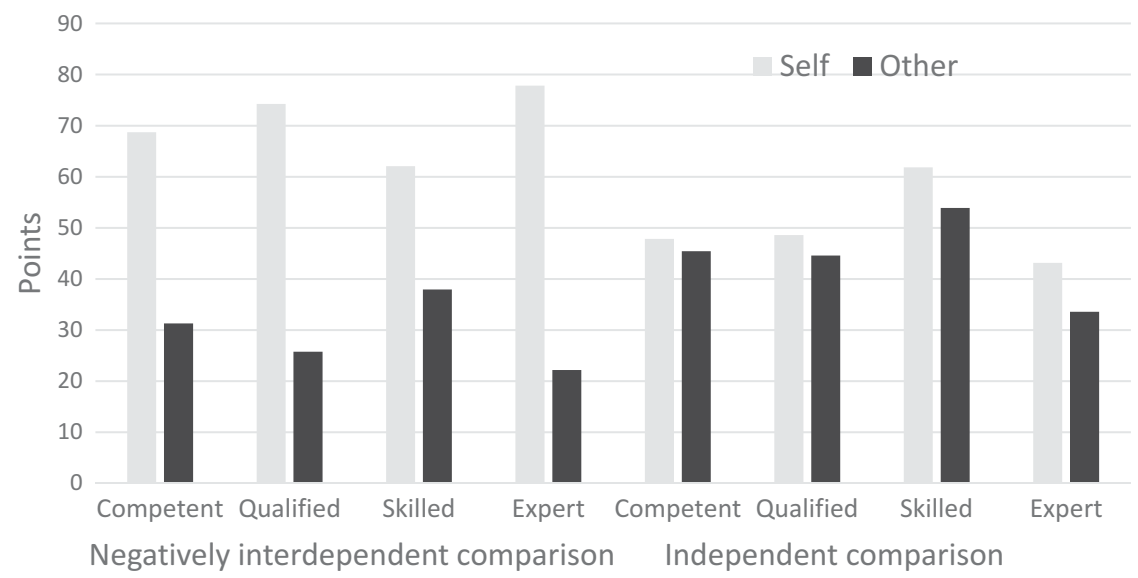

Figure 5. Mean points per trait, allocated to oneself and the other as a function of in (ter)dependence (based on Butera \& Mugny, 1995).

than in the independence condition. To sum up, this experiment showed that competition resulted in both increased competence threat and increased use of confirmation.

\section{Expertise and competence threat}

Support for these results can be found in more recent research. Toma, Vasiljevic, Oberlé, and Butera (2013) gave their participants the road accident case described above (Toma \& Butera, 2009). About 144 French psychology students participated in three-person groups. Cooperation and competition were manipulated again through positive and negative goal interdependence. In addition, this study manipulated what has been called expertise assignment (e.g., Stewart \& Stasser, 1995): In each group, participants were informed (vs. not) that each of them had privileged access to unique information, thereby attributing specific competence to each one of them. Two measures are relevant to the present discussion. The first one is the self-other difference in perceived competence (the difference between the participant's own estimated competence and that of the others, on 9point scales), with a higher score indicating a greater differentiation in reported competence in favour of oneself. The second measure is the proportion of unshared information pooled during group discussion. Unshared information is important as it contains the elements that may lead a person to disconfirm the sub-optimal initial solutions, and failure to pool them is bound to impede disconfirmation and the discovery of the correct solution.

Results revealed a stronger self-other difference in reported competence when participants worked in a competitive (vs. cooperative) group, with 
Table 3. Least squares regression results for the mediated moderation model for the proportion of unshared information (from Toma, Vasiljevic, Oberlé, and Butera, 2013, British Journal of Social Psychology, 52, 161-172. Copyright by Wiley. Reprinted with permission).

\begin{tabular}{|c|c|c|c|c|c|c|}
\hline \multirow[b]{2}{*}{ Predictors } & \multicolumn{2}{|c|}{$\begin{array}{l}\text { Equation } 1 \\
\text { (criterion } \\
\text { proportion of } \\
\text { unshared } \\
\text { information) } \\
\end{array}$} & \multicolumn{2}{|c|}{$\begin{array}{l}\text { Equation } 2 \\
\text { (criterion } \\
\text { perception of } \\
\text { self-other } \\
\text { competence) } \\
\end{array}$} & \multicolumn{2}{|c|}{$\begin{array}{l}\text { Equation } 3 \\
\text { (criterion } \\
\text { proportion of } \\
\text { unshared } \\
\text { information) }\end{array}$} \\
\hline & $\beta$ & $t$ & $\beta$ & $t$ & $\beta$ & $t$ \\
\hline Expertise & -.08 & -.76 & .14 & 1.14 & .03 & .29 \\
\hline Goals & .69 & $6.93^{* * *}$ & -.40 & $-3.21^{* *}$ & .60 & $5.74^{* *}$ \\
\hline Expertise X Goals & .28 & $2.83^{* *}$ & -.36 & $-2.87^{* *}$ & .17 & 1.62 \\
\hline Perception of self-other competence & & & & & -.24 & $-2.10^{*}$ \\
\hline Perception of self-other competence X Goals & & & & & .18 & 1.75 \\
\hline
\end{tabular}

Note: ${ }^{*} p<.05 .{ }^{* *} p<.01 .{ }^{* * *} p<.001$.

(vs. without) expertise assignment. Further analyses pointed out that the effect was especially due to a devaluing of the other's competence, in a sort of downward social comparison typical of threatening contexts (Wills, 1981). Thus, competition with assigned experts appears to be particularly threatening for the self, as compared to the other conditions. Moreover, it was also found that the proportion of unshared information was lower when participants worked in a competitive (vs. cooperative) group, with (vs. without) expertise assignment. And a mediated moderation analysis showed that this effect was partially mediated by self-other difference in perceived competence (see Table 3). Competition led participants with assigned expertise to exaggerate the other's inferiority in terms of competence, which resulted in a reduced proportion of pooling of unshared information, the kind of information that could lead during group discussion to disconfirm suboptimal solutions.

\section{Summary}

The third implication, namely that if our proposition is true, then, confirmation should occur to a larger extent when competition is threatening for one's feelings of competence, also received support from the reviewed results. The studies presented in this section suggest that competition is threatening for one's feelings of competence and leads to increased use of confirmation in reasoning and decision-making. When people are threatened with appearing less competent in a competition, they make sure that their hypothesis, choice or point of view receives the support afforded by confirmation. 


\section{Contributions to the initial questions}

The body of research presented in the previous section supports the view that confirmation occurs especially in a specific social situation (competition), with a specific appraisal of that situation (threat), and because a specific trait (competence) is concerned by the threat. These observations provide support for the claim that confirmation has a specific social function: That of coping with the threat of one's feelings of competence derived from competition. Competence is an important human need - some even say that it is one of the three universal psychological needs (Ryan \& Deci, 2000a) - and people are highly motivated to protect it (Steele, 1988; Tesser, 1988). Most social interactions are comparative (Festinger, 1954) and evaluative (Butera \& Darnon, 2017), as people are motivated to achieve a positive self-evaluation (Muller \& Butera, 2007). However, as noted by Tesser (1988), competence is also a resource that is highly valued in industrialised societies, in that it refers to the potential contribution of an individual to the production system, and therefore it is differentially rewarded on the basis of a merit principle (Deutsch, 1979). The consequence of both the importance of competence and its centrality in social rewards is that in most evaluative settings - school, university, work, sports, etc., where rewards, grades, awards, positions, advancements, medals are at stake - people view others as potential competitors and, unless they are clearly reassured as per their superiority, they feel threatened in their competence. This explains why confirmation is so pervasive: It allows us to bring consistent support for our judgments, in pervasively competitive and threatening social encounters.

It should be noted at this point that "consistent support for our judgments" does not mean that confirmation makes us more accurate. One might argue that our results merely show that people prefer information that serves their goal. When the goal is to win rather than to be accurate, they use confirmation to a larger extent. If the goal was to win by being accurate, competition would reduce confirmation. However, all the tasks used in our research programme were problem-solving tasks, tasks that require the participants to discover the correct or the best answer. In this respect, a problem-solving task implies that in order to win one has to find a correct answer, as in the aforementioned study by Toma and Butera (2009) where the goal was to outperform the others by being the first in the group to offer the best solution. The results presented above revealed that in competitive situations, participants prefer the soothing attempt to confirm their hypothesis rather than the discovery of the correct answer.

Let us now discuss how our conclusions, and the work that has prompted them, may contribute to the questions formulated in the first section of this article. 


\section{Is confirmation the result of cognitive failure?}

The research discussed in this article shows that the prevalence of confirmation use can be reduced without changing the nature of the task, or providing specific training, or making it easier. We showed that the use of confirmation diminished in cooperative environments (e.g., Toma \& Butera, 2009) and in the case of a comparison with a non-threatening other (e.g., Sommet et al., 2015), while the task was not altered. Thus, confirmation cannot be considered the mere result of some cognitive failure or limitation, as its occurrence is reduced when it is less needed to cope with a competitive environment that threatens one's competence. It is indeed a cognitive process that interacts with motivational, social and societal factors.

The present results are compatible with the theory of mental models, which implies that confirmation is more likely to appear than disconfirmation because it requires building one mental model instead of several (Johnson-Laird, 1983). Indeed, building several mental models requires a greater share of cognitive resources than building only one. However, pursuing competitive goals also taxes cognitive resources, as shown by a study in which instructions to pursue performance goals (vs. not) depleted the working memory necessary for the task (Crouzevialle \& Butera, 2013; see also, 2017). Therefore, reducing the distracting effect of competition may make cognitive resources available for building more complex series of mental models, and allow problem-solvers to envision the alternative hypotheses necessary to use disconfirmation in a diagnostic way. In other words, the use of disconfirmation need not make the task easier but make the social environment less threatening.

\section{Is confirmation the result of motivational prioritisation?}

Motivation is crucial, but it is important to stress the specific goal that is pursued when using confirmation. Motivation for cognitive consistency (Evans, 1982), need for nonspecific closure (Kruglanski, 1990) and the motivation to avoid cognitive dissonance (Frey, 1986) are certainly important motives and predict the appearance of several forms of confirmatory behaviour. However, the research discussed in this article reveals the importance of clearly identifying the specific goal involved in the use of confirmation, in order to understand its social function. Cognitive consistency, need for closure and cognitive dissonance are broad motivations that predict a wide array of behaviours, well beyond confirmation. In this respect, they do not allow us to specify the function of the target behaviour.

On the contrary, our findings show that confirmation occurs especially in a competitive environment, when competition threatens one's 
competence, which allows us to uncover that confirmation has a specific protective function. Stated otherwise, it may very well be that individuals who set confirmatory tests of their hypotheses, or seek out confirmatory information for their expectations, are not just motivated by a need for nonspecific closure to stop hypothesis generation and testing, but rather by the need for the specific closure (Kruglanski, 1990) to provide the self with a confirmatory buffer against the danger of a potentially negative evaluation of one's competence. Likewise, selective exposure to information might be motivated by a more specific desire than that of reducing the generic discomfort following dissonance, namely the desire to protect one's competence.

\section{Is confirmation a pragmatic strategy?}

Yes, it is, but not a generic strategy. We have seen that in the argumentative theory (Mercier, 2016) reasoning is viewed as the cognitive function that allows communication, and confirmation as a strategy that allows people to produce self-serving arguments during communication. The research presented in this article, however, showed that confirmation does not appear in every conversation or in any form of communication: It appears especially in competitive encounters, and when competence is threatened by the possibility of losing the argument. In sum, we recognise that confirmation is a motivated cognitive process and that it is used to achieve a social function during communication, but our results revealed that both motivation and social function need to be specified. Confirmation proceeds from the specific need to cope with threatening competitive settings and has the specific function of coping with the threat to one's feelings of competence.

\section{Limitations and research agenda}

The present article has articulated a substantial number of studies, spanning more than 25 years, yet still so much is left to do. The first limitation we need to highlight is an important one. We claimed that the function of confirmation needed to be a specific one, and this is why we proposed that confirmation is an adaptive mechanism allowing one to cope with one's threatened feelings of competence in case of competition. This is indeed a specific proposition, especially in comparison with other existing accounts, but it contains an element of indecision: "coping" is a non-specific reaction. We would have preferred to be able to clarify whether coping takes the form of self-enhancement or self-protection, namely "interests that people have in advancing one or more self-components or defending themselves against negative self-views" (Alicke \& Sedikides, 2009). However, the present results do not allow us to decide, as we have observed both 
phenomena. In Butera and Mugny (1995) and Sommet et al. (2015), confirmation appears to serve a self-enhancement purpose, as it proceeds from the assertion of one's own point of view against that of another. In Butera et al. (1996), it appears to serve a self-protection purpose, as the largest proportion of confirmation occurs in the condition where participants have also followed the most the influence source's rule (these results were not reported here but are available in the original article). In a way, confirmation protects the consensus achieved with the source.

When can one expect confirmation to serve self-enhancement vs. selfprotection? A possible answer lies in the underlying motives driving people to use confirmation in competitive situations. Competition is known to predict two kinds of performance goals - a distinction that we did not highlight in the present article, but that might be useful at this point namely performance-approach and performance-avoidance goals (Murayama \& Elliot, 2012; see Elliot \& McGregor, 2001; and footnote 1). Sommet et al. (2014) have shown that performance-approach goals predict a form of conflict regulation based on self-enhancement, whereas performance-avoidance goals predict a form of conflict regulation based on selfprotection. It is possible to interpret the possibly self-enhancing function of confirmation in Butera and Mugny (1995) and Sommet et al. (2015) by pointing to the fact that, in these studies, disagreement was set from the beginning and difficult to escape, and competitive motives needed to enhance one's point of view. The possibly self-protecting function of confirmation in Butera et al. (1996) might, in turn, be due to the fact that compliance was possible and competitive motives could be diverted by consensus with a superior source. Future research would provide a useful contribution if a study was designed to disentangle the self-enhancing vs. self-protecting functions of confirmation.

Another important limitation is that the present proposition is limited to an inter-individual level of analysis (Doise, 1986). However, we have seen that confirmation also takes place in group decision-making (Frey \& Schulz-Hardt, 2001), and motivations such as need for closure may intervene at the group level and be shaped, as in Schulz-Hardt et al. (2000), by group homogeneity (Kruglanski, Shah, Pierro, \& Mannetti, 2002). Interestingly, when studying concurrence-seeking in groups, the groupthink phenomenon, Janis (1972) proposed that homogenous groups would be more at risk of confirmatory behaviours such as selective exposure to information. He also noted that external threats, such as a competitive environment, might also be an aggravating factor. An important extension of the present programme would be to move to the intergroup level of analysis and test the hypothesis that confirmation in group decision-making is an adaptive mechanism allowing to cope with the group's threatened feelings of competence in case of intergroup competition. 
These limitations notwithstanding, the research programme we reviewed allowed us to propose an account of confirmation that suggests one reason why this phenomenon is so pervasive, namely that people test their hypotheses in particularly competitive environments and societies that threaten an extremely important feature of our self: Competence. In this respect, the proposed account stems from a socio-cognitive approach in social psychology (Doise \& Mugny, 1984), which considers that cognitive processes are influenced by a dense network of motivational, interpersonal, intergroup and societal factors (Pérez \& Mugny, 1996), with influences that go in both directions (Butera, Sommet, \& Darnon, in press).

\section{Funding}

The preparation of this work has been supported by the Swiss National Science Foundation.

\section{References}

Alicke, M. D., \& Sedikides, C. (2009). Self-enhancement and self-protection: What they are and what they do. European Review of Social Psychology, 20, 1-48.

Andersen, S. M., \& Chen, S. (2002). The relational self: An interpersonal socialcognitive theory. Psychological Review, 109, 619-645.

Anderson, J. R. (1990). The adaptive character of thought. Hillsdale, NJ: Laurence Erlbaum Associates.

Beyth-Marom, R., \& Fischhoff, B. (1983). Diagnosticity and pseudodiagnosticity. Journal of Personality and Social Psychology, 45, 1185.

Blascovich, J., Mendes, W. B., Hunter, S. B., Lickel, B., \& Kowai-Bell, N. (2001). Perceiver threat in social interactions with stigmatized others. Journal of Personality and Social Psychology, 80, 253-267.

Brown, J. D. (1986). Evaluations of self and others: Self-enhancement biases in social judgments. Social Cognition, 4, 353-376. doi:10.1521/soco.1986.4.4.353

Butera, F., \& Mugny, G. (2001). Conflicts and social influences in hypothesis testing. In C. De Dreu \& N. De Vries (Eds.), Group consensus and minority influence: Implications for innovation (pp. 160-182). Oxford, UK: Blackwell.

Butera, F., Darnon, C., \& Mugny, G. (2011). Learning from conflict. In J. Jetten \& M. Hornsey (Eds.), Rebels in groups: Dissent, deviance, difference and defiance (pp. 36-53). Oxford, UK: Wiley-Blackwell.

Butera, F., \& Darnon, C. (2017). Competence assessment, social comparison and conflict regulation. In A. Elliot, C. Dweck, \& D. Yaeger (Eds.), Handbook of competence and motivation: Theory and application (2nd edn., pp. 192-213). New York: Guilford Press.

Butera, F., \& Mugny, G. (1992). Influence minoritaire et falsification. A propos de "Quelques réflexions psycho-sociologiques sur une controverse scientifique" de B. Matalon [Minority influence and falsification. Considerations on "Quelques réflexions psycho-sociologiques sur une controverse scientifique" by B. Matalon]. International Review of Social Psychology, 5, 115-132.] 
Butera, F., \& Mugny, G. (1995). Conflict between incompetences and influence of a low-competence source in hypothesis testing. European Journal of Social Psychology, 25, 457-462.

Butera, F., Mugny, G., Legrenzi, P., \& Pérez, J. A. (1996). Majority and minority influence, task representation, and inductive reasoning. British Journal of Social Psychology, 35, 123-136.

Butera, F., Sommet, N., \& Darnon, C. (in press). Socio-cognitive conflict regulation: How to make sense of diverging ideas. Current Direction in Psychological Science.

Caverni, J.-P., Fabre, J.-M., \& Gonzales, M. (Eds). (1990). Cognitive biases. Amsterdam: Elsevier.

Chater, N., \& Oaksford, M. (1999). Ten years of the rational analysis of cognition. Trends in Cognitive Sciences, 3, 57-65.

Cheng, P. W., \& Holyoak, K. J. (1985). Pragmatic reasoning schemas. Cognitive Psychology, 17, 391-416.

Chernyshenko, O. S., Miner, A. G., Baumann, M. R., \& Sniezek, J. A. (2003). The impact of information distribution, ownership, and discussion on group member judgment: The differential cue weighting model. Organizational Behavior and Human Decision Processes, 91, 12-25.

Cosmides, L. (1989). The logic of social exchange: Has natural selection shaped how humans reason? Studies with the Wason selection task. Cognition, 31, 187-276.

Crouzevialle, M., \& Butera, F. (2013). Performance-approach goals deplete working memory and impair cognitive performance. Journal of Experimental Psychology: General, 142, 666-678.

Crouzevialle, M., \& Butera, F. (2017). Performance goals and task performance: Integrative considerations on the distraction hypothesis. European Psychologist, 22, 73-82.

Dardenne, B., \& Leyens, J. P. (1995). Confirmation bias as a social skill. Personality and Social Psychology Bulletin, 21, 1229-1239.

Darley, J. M., \& Gross, P. H. (1983). A hypothesis-confirming bias in labeling effects. Journal of Personality and Social Psychology, 44, 20-33.

Darnon, C., Muller, D., Schrager, S., Pannuzzo, N., \& Butera, F. (2006). Mastery and performance goals predict epistemic and relational conflict regulation. Journal of Educational Psychology, 98, 766-776.

De Vries, N. K., De Dreu, C. K., Gordijn, E., \& Schuurman, M. (1996). Majority and minority influence: A dual role interpretation. European Review of Social Psychology, 7(1), 145-172.

Deutsch, M. (1973). The resolution of conflict: Constructive and destructive processes. New Haven, CT: Yale University Press.

Deutsch, M. (1979). Education and distributive justice: Some reflections on grading systems. American Psychologist, 34, 391-401.

Ditto, P. H., \& Lopez, D. F. (1992). Motivated skepticism: Use of differential decision criteria for preferred and nonpreferred conclusions. Journal of Personality and Social Psychology, 63, 568-584.

Doise, W. (1986). Levels of explanation in social psychology. Cambridge, UK: Cambridge University Press.

Doise, W., \& Mugny, G. (1984). The social development of the intellect. Amsterdam: Elsevier.

Elliot, A. J., \& McGregor, H. A. (2001). A $2 \times 2$ achievement goal framework. Journal of Personality and Social Psychology, 80, 501-519. 
Evans, J. S. B. T. (1982). The psychology of deductive reasoning. London, UK: Routledge \& Kegan Paul.

Evans, J. St. B. T. (1989). Bias in human reasoning: Causes and consequences. Hove, UK: Erlbaum.

Festinger, L. (1954). A theory of social comparison processes. Human Relations, 7, 117-140.

Fiedler, K. (1996). Explaining and simulating judgment biases as an aggregation phenomenon in probabilistic, multiple-cue environments. Psychological Review, 103, 193-214.

Fiedler, K. (2008). The ultimate sampling dilemma in experience-based decision making. Journal of Experimental Psychology: Learning, Memory, and Cognition, 34, 186-203.

Fiedler, K., Walther, E., \& Nickel, S. (1999). The auto-verification of social hypotheses: Stereotyping and the power of sample size. Journal of Personality and Social Psychology, 77, 5-18.

Frey, D. (1986). Recent research on selective exposure to information. In L. Berkowitz (Ed.), Advances in experimental social psychology (Vol. 19, pp. 4180). New York, NY: Academic Press.

Frey, D., \& Schulz-Hardt, S. (2001). Confirmation bias in group information seeking and its implications for decision making in administration, business and politics. In F. Butera \& G. Mugny (Eds.), Social influence in social reality (pp. 53-74). Göttingen: Hogrefe \& Huber Publishers.

Gardner, H. E. (2008). The mind's new science: A history of the cognitive revolution. New Yourk, NY: Basic Books.

Gigerenzer, G., \& Hug, K. (1992). Reasoning about social contracts: Cheating and perspective change. Cognition, 43, 127-171.

Gorman, M., \& Gorman, M. E. (1984). A comparison of confirmatory, disconfirmatory and control strategy on Wason's 2-4-6 task. Quarterly Journal of Experimental Psychology, 36, 629-648.

Greenberg, J., Solomon, S., \& Pyszczynski, T. (1997). Terror management theory of self-esteem and cultural worldviews: Empirical assessments and conceptual refinements. In M. P. Zanna (Ed.), Advances in experimental social psychology (Vol. 29, pp. 61-139). New York: Academic Press.

Greenwald, A. G., Pratkanis, A. R., Leippe, M. R., \& Baumgardner, M. H. (1986). Under what conditions does theory obstruct research progress? Psychological Review, 93, 216-229.

Greitemeyer, T., \& Schulz-Hardt, S. (2003). Preference-consistent evaluation of information in the hidden profile paradigm: Beyond group-level explanations for the dominance of shared information in group decisions. Journal of Personality and Social Psychology, 84, 322-339.

Griggs, R. A., \& Cox, J. R. (1982). The elusive thematic-materials effect in Wason's selection task. British Journal of Psychology, 73, 407-420.

Hahn, U., \& Oaksford, M. (2007). The rationality of informal argumentation: A Bayesian approach to reasoning fallacies. Psychological Review, 114, 704-732.

Hass, R. G. (1981). Effects of source characteristics on cognitive responses and persuasion. In R. E. Petty, T. M. Ostrom, \& T. C. Brock (Eds.), Cognitive responses in persuasion (pp. 141-172). Hillsdale, NJ: Erlbaum.

Hayek, A. S., Toma, C., Oberlé, D., \& Butera, F. (2014). The effect of grades on the preference effect: Grading reduces consideration of disconfirming evidence. Basic and Applied Social Psychology, 36, 544-552. 
Hayek, A. S., Toma, C., Oberlé, D., \& Butera, F. (2015). Grading hampers cooperative information sharing in group problem solving. Social Psychology, 46, 121-131.

Heine, S. J., Proulx, T., \& Vohs, K. D. (2006). The meaning maintenance model: On the coherence of social motivations. Personality and Social Psychology Review, 10, 88-110.

Hogg, M. A., \& Mullin, B.-A. (1999). Joining groups to reduce uncertainty: Subjective uncertainty reduction and group identification. In D. Abrams \& M. A. Hogg (Eds.), Social identity and social cognition (pp. 249-279). Malden: Blackwell Publishing.

Holyoak, K. J., \& Spellman, B. A. (1993). Thinking. Annual Review of Psychology, 44, 265-315.

Huguet, P., Mugny, G., \& Pérez, J. A. (1991). Influence sociale et processus de décentration [Social influence and decentring processes]. Bulletin De Psychologie, 45, 155-163.

Inhelder, B., \& Piaget, J. (1958). The growth of logical thinking from childhood to adolescence. London, UK: Routledge and Kegan Paul.

Janis, I. L. (1972). Victims of groupthink: A psychological study of foreign-policy decisions and fiascoes. Oxford, UK: Houghton Mifflin.

Johnson-Laird, P. N. (1983). Mental models. Cambridge, UK: Cambridge University Press.

Johnson-Laird, P. N., Legrenzi, P., \& Legrenzi, M. S. (1972). Reasoning and a sense of reality. British Journal of Psychology, 63, 395-400.

Jonas, E., Schulz-Hardt, S., Frey, D., \& Thelen, N. (2001). Confirmation bias in sequential information search after preliminary decisions: An expansion of dissonance theoretical research on selective exposure to information. Journal of Personality and Social Psychology, 80, 557-571.

Jussim, L. (1986). Self-fulfilling prophecies: A theoretical and integrative review. Psychological Review, 93, 429-445.

Kay, A. C., Gaucher, D., McGregor, I., \& Nash, K. (2010). Religious belief as compensatory control. Personality and Social Psychology Review, 14, 37-48.

Klayman, J. (1995). Varieties of confirmation bias. In D. L. Medin, J. Busemeyer, \& R. Hastie (Eds.), Decision making from a cognitive perspective (pp. pp. 385-418). New York, NY: Academic Press.

Klayman, J., \& Ha, Y. W. (1989). Hypothesis testing in rule discovery: Strategy, structure, and content. Journal of Experimental Psychology: Learning, Memory, and Cognition, 15, 596-604.

Klayman, J., \& Ha, Y.-W. (1987). Confirmation, disconfirmation and information in hypothesis testing. Psychological Review, 94, 211-228.

Kruglanski, A. (1980). Lay epistemo-logic; process and contents: Another look at attribution theory. Psychological Review, 87, 70-87.

Kruglanski, A. (1989). Lay epistemics and human knowledge: Cognitive and motivational bases. New York, NY: Springer Science \& Business Media.

Kruglanski, A. (1990). Motivations for judging and knowing. Implications for causal attribution. In E. T. Higgins \& R. M. Sorrentino (Eds.), Handbook for motivation and cognition (Vol. 2, pp. 333-368). New York, NY: Guilford Press.

Kruglanski, A. (2013). The psychology of closed mindedness. New York, NY: Psychology Press.

Kruglanski, A., \& Freund, T. (1983). The freezing and unfreezing of lay inferences: Effects of impressional primacy, ethnic stereotyping, and numerical anchoring. Journal of Experimental Social Psychology, 19, 448-468. 
Kruglanski, A., Shah, J. Y., Pierro, A., \& Mannetti, L. (2002). When similarity breeds content: Need for closure and the allure of homogeneous and selfresembling groups. Journal of Personality and Social Psychology, 83, 648-662.

Kunda, Z. (1990). The case for motivated reasoning. Psychological Bulletin, 108, 480-498.

Laughlin, P. R., VanderStoep, S. W., \& Hollingshead, A. B. (1991). Collective versus individual induction: Recognition of truth, rejection of error, and collective information processing. Journal of Personality and Social Psychology, 61, 50-67.

Le Mens, G., \& Denrell, J. (2011). Rational learning and information sampling: On the "naivety" assumption in sampling explanations of judgment biases. Psychological Review, 118, 379-392.

Lee, D. S., Kim, E., \& Schwarz, N. (2015). Something smells fishy: Olfactory suspicion cues improve performance on the Moses illusion and Wason rule discovery task. Journal of Experimental Social Psychology, 59, 47-50.

Legrenzi, P., Butera, F., Mugny, G., \& Pérez, J. A. (1991). Majority and minority influence in inductive reasoning: A preliminary study. European Journal of Social Psychology, 21, 359-363.

Legrenzi, P., Girotto, V., \& Johnson-Laird, P. N. (1993). Focussing in reasoning and decision making. Cognition, 49, 37-66.

Legrenzi, P., \& Legrenzi, M. (1991). Reasoning and social psychology: From mental logic to a perspective approach. Intellectica, 11, 53-80.

Lemaine, G. (1974). Social differentiation and social originality. European Journal of Social Psychology, 4, 17-52.

Lemaine, G. (1975). Dissimilation and differential assimilation in social influence (situations of "normalization"). European Journal of Social Psychology, 5, 93120.

Leyens, J. P., Dardenne, B., Yzerbyt, V., Scaillet, N., \& Snyder, M. (1999). Confirmation and disconfirmation: Their social advantages. European Review of Social Psychology, 10, 199-230.

Light, P., Girotto, V., \& Legrenzi, P. (1990). Children's reasoning on conditional promises and permissions. Cognitive Development, 5, 369-383.

Lynch, M. F., Jr., Plant, R. W., \& Ryan, R. M. (2005). Psychological needs and threat to safety: Implications for staff and patients in a psychiatric hospital for youth. Professional Psychology: Research and Practice, 36, 415-425.

Maggi, J., Butera, F., Legrenzi, P., \& Mugny, G. (1998). Relevance of information and social influence in the pseudodiagnosticity bias. Swiss Journal of Psychology, 57(3), 188-199.

Mahoney, M. J. (1976). Scientist as subject: The psychological imperative. Cambridge: Ballinger.

Mahoney, M. J. (1979). Psychology of the scientist: An evaluative review. Social Studies of Science, 9, 349-375.

Mayo, R. (2015). Cognition is a matter of trust: Distrust tunes cognitive processes. European Review of Social Psychology, 26, 283-327.

Mayo, R., Alfasi, D., \& Schwarz, N. (2014). Distrust and the positive test heuristic: Dispositional and situated social distrust improves performance on the Wason rule discovery task. Journal of Experimental Psychology: General, 143, 985-990.

McDonald, J. (1990). Some situational determinants of hypothesis-testing strategies. Journal of Experimental Social Psychology, 26, 255-274.

Mercier, H. (2016). The argumentative theory: Predictions and empirical evidence. Trends in Cognitive Sciences, 20, 689-700. 
Mercier, H., \& Sperber, D. (2011). Why do humans reason? Arguments for an argumentative theory. Behavioral and Brain Sciences, 34, 57-74.

Merton, R. K. (1948). The self-fulfilling prophecy. The Antioch Review, 8, 193-210.

Miller, G. A. (2003). The cognitive revolution: A historical perspective. Trends in Cognitive Sciences, 7, 141-144.

Mischel, W., Ebbesen, E. B., \& Zeiss, A. M. (1973). Selective attention to the self: Situational and dispositional determinants. Journal of Personality and Social Psychology, 27, 129-142.

Mitroff, I. (1974). Norms and couter-norms in a selected group of Apollo moon scientists: A case study of the ambivalence of scientists. American Sociological Review, 39, 579-595.

Muller, D., \& Butera, F. (2007). The distracting effect of self-evaluation threat in coaction and social comparison. Journal of Personality and Social Psychology, 93, 194-211.

Muller, D., \& Fayant, M. P. (2010). On being exposed to superior others: Consequences of self-threatening upward social comparisons. Social and Personality Psychology Compass, 4, 621-634.

Murayama, K., \& Elliot, A. J. (2012). The competition-Performance relation: A meta-analytic review and test of the opposing processes model of competition and performance. Psychological Bulletin, 138, 1035-1070.

Mynatt, C. R., Doherty, M. E., \& Tweney, R. D. (1977). Confirmation bias in a simulated research environment: An experimental study of scientific inference. Quarterly Journal of Experimental Psychology, 29, 85-95.

Nemeth, C. (1986). Differential contributions of majority and minority influence. Psychological Review, 93, 23-32.

Oaksford, M., \& Chater, N. (1994). A rational analysis of the selection task as optimal data selection. Psychological Review, 101, 608.

Oswald, M. E., \& Grosjean, S. (2004). Confirmation bias. In Pohl (Ed.), Cognitive illusions: A handbook on fallacies and biases in thinking, judgement and memory (pp. 79-96). New York, NY: Psychology Press.

Pérez, J. A., \& Mugny, G. (1996). The conflict elaboration theory of social influence. In E. H. Witte \& J. H. Davis (Eds.), Understanding group behavior (Vol. 2): Small group processes and interpersonal relations (pp. 191-210). Hillsdale, NJ: Lawrence Erlbaum Associates.

Pulfrey, C., Buchs, C., \& Butera, F. (2011). Why grades engender performance avoidance goals: The mediating role of autonomous motivation. Journal of Educational Psychology, 103, 683-700.

Pulfrey, C., Darnon, C., \& Butera, F. (2013). Autonomy and task performance: Explaining the impact of grades on intrinsic motivation. Journal of Educational Psychology, 105, 39-57.

Pyszczynski, T., \& Greenberg, J. (1987). Toward an integration of cognitive and motivational perspectives on social inference: A biased hypothesis-testing model. In L. Berkowitz (Ed.), Advances in experimental social psychology (Vol. 20, pp. 297-340). San Diego, CA: Academic Press.

Rips, L. J. (1994). The psychology of proof: Deductive reasoning in human thinking. Boston, MA: MIT Press.

Rosenthal, R. (1994). Interpersonal expectancy effects: A 30-year perspective. Current Directions in Psychological Science, 3, 176-179. 
Ryan, R. M., \& Deci, E. L. (2000a). Self-determination theory and the facilitation of intrinsic motivation, social development, and well-being. American Psychologist, $55,68-78$.

Ryan, R. M., \& Deci, E. L. (2000b). The darker and brighter sides of human existence: Basic psychological needs as a unifying concept. Psychological Inquiry, 11, 319-338.

Schulz-Hardt, S., Frey, D., Lüthgens, C., \& Moscovici, S. (2000). Biased information search in group decision making. Journal of Personality and Social Psychology, 78, 655-669.

Schwartz, S. H. (2007). Cultural and individual value correlates of capitalism: A comparative analysis. Psychological Inquiry, 18, 52-57.

Snyder, M. (1981). Seek, and ye shall find: Testing hypotheses about other people. In E. T. Higgins, C. P. Herman, \& M. P. Zanna (Eds.), Social cognition. The Ontario symposium(pp. 277-303). Hillsdale, NJ: Erlbaum.

Snyder, M. (1984). When belief creates reality. In L. Berkowitz (Ed.), Advances in experimental social psychology (Vol. 18, pp. 248-306). New York: Academic Press.

Snyder, M., \& Stukas, A. A., Jr. (1999). Interpersonal processes: The interplay of cognitive, motivational, and behavioral activities in social interaction. Annual Review of Psychology, 50, 273-303.

Snyder, M., \& Swann, W. B. (1978). Behavioral confirmation in social interaction: From social perception to social reality. Journal of Experimental Social Psychology, 14, 148-162.

Sommet, N., Darnon, C., \& Butera, F. (2015). To confirm or to conform? Performance goals as a regulator of conflict with more competent others. Journal of Educational Psychology, 107, 580-598.

Sommet, N., Darnon, C., Mugny, G., Quiamzade, A., Pulfrey, C., Dompnier, B., \& Butera, F. (2014). Performance goals in conflictual social interactions: Toward the distinction between two modes of relational conflict regulation. British Journal of Social Psychology, 53, 134-153.

Stanovich, K. E., West, R. F., \& Toplak, M. E. (2013). Myside bias, rational thinking, and intelligence. Current Directions in Psychological Science, 22, 259-264.

Stasser, G., \& Titus, W. (1985). Pooling of unshared information in group decision making: Biased information sampling during discussion. Journal of Personality and Social Psychology, 48, 1467-1478.

Steele, C. M. (1988). The psychology of self-affirmation: Sustaining the integrity of the self. In L. Berkowitz (Ed.), Advances in experimental social psychology (Vol. 21, pp. 261-302). San Diego: Academic Press.

Stewart, D. D., \& Stasser, G. (1995). Expert role assignment and information sampling during collective recall and decision making. Journal of Personality and Social Psychology, 69, 619-628.

Tesser, A. (1988). Toward a self-evaluation maintenance model of social behavior. In L. Berkowitz (Ed.), Advances in experimental social psychology (Vol. 21, pp. pp. 181-227). San Diego, CA: Academic Press.

Tesser, A., Millar, M., \& Moore, J. (1988). Some affective consequences of social comparison and reflection processes: The pain and pleasure of being close. Journal of Personality and Social Psychology, 54, 49-61.

Toma, C., Bry, C., \& Butera, F. (2013b). Because I'm worth it! (more than others. . .): Cooperation, competition and ownership bias in group-decision making. Social Psychology, 44, 248-255. 
Toma, C., \& Butera, F. (2009). Hidden profiles and concealed information: Strategic information sharing and use in group decision making. Personality and Social Psychology Bulletin, 35, 793-806.

Toma, C., \& Butera, F. (2015). Cooperation versus competition effects on information sharing and use in group decision-making. Social and Personality Psychology Compass, 9, 455-467.

Toma, C., Gilles, I., \& Butera, F. (2013a). Strategic use of preference confirmation in group decision making: The role of competition and dissent. British Journal of Social Psychology, 52, 44-63.

Toma, C., Vasiljevic, D., Oberlé, D., \& Butera, F. (2013). Assigned experts with competitive goals withhold information in group decision making. British Journal of Social Psychology, 52, 161-172.

Tomaka, J., Blascovich, J., Kelsey, R. M., \& Leitten, C. L. (1993). Subjective, physiological, and behavioral effects of threat and challenge appraisal. Journal of Personality and Social Psychology, 65, 248-260.

Tooby, J., \& Cosmides, L. (1992). The psychological foundations of culture. In J. Barkow, L. Cosmides, \& J. Tooby (Eds.), The adapted mind: Evolutionary pschology and the generation of culture (pp. 19-136). New York: Oxford University Press.

Trope, Y., \& Mackie, D. M. (1987). Sensitivity to alternatives in social hypothesistesting. Journal of Experimental Social Psychology, 23, 445-459.

Tweney, R. D., Doherty, M. E., Worner, W. J., Pliske, D. B., Mynatt, C. R., Gross, K. A., \& Arkkelin, D. L. (1980). Strategies of rule discovery in an inference task. Quarterly Journal of Experimental Psychology, 32, 109-123.

Wason, P. C. (1960). On the failure to eliminate hypotheses in a conceptual task. The Quarterly Journal of Experimental Psychology, 12, 255-274.

Wason, P. C. (1966). Reasoning. In B. M. Foss (Ed.), New horizons in psychology (pp. 135-151). Harmondsworth, UK: Penguin.

Wason, P. C., \& Johnson-Laird, P. N. (1972). Psychology of reasoning: Structure and content. Cambridge, MA: Harvard University Press.

Wills, T. A. (1981). Downward comparison principles in social psychology. Psychological Bulletin, 90, 245-271.

Yzerbyt, V. Y., Coull, A., \& Rocher, S. J. (1999). Fencing off the deviant: The role of cognitive resources in the maintenance of stereotypes. Journal of Personality and Social Psychology, 77, 449-462. 